\title{
THE EFFECTS OF A VEGETARIAN DIET ON IRON STATUS IN FEMALE STUDENTS
}

\author{
A Thesis \\ presented to \\ the Faculty of California Polytechnic State University, \\ San Luis Obispo
}

In Partial Fulfillment of the Requirements for the Degree Master of Science in Agriculture, with Specialization in Food Science and Nutrition

by

Kimberly Britt Grage Englehardt August 2008 
(C) 2008

Kimberly Britt Grage Englehardt ALL RIGHTS RESERVED 
TITLE:

AUTHOR:

DATE SUBMITTED:

COMMITTEE CHAIR:

COMMITTEE MEMBER:

COMMETTEE MEMBER:
The Effects of a Vegetarian Diet on Iron Status in Female Students

Kimberly Britt Grage Englehardt

August 2008

Susan Hawk, PhD, RD

Lisa Nicholson, $\mathrm{PhD}, \mathrm{RD}$

Pat Hosegood Martin, Ed.D. 


\begin{abstract}
ABSRACT
The Effects of a Vegetarian Diet on Iron Status in Female Students Kimberly Britt Grage Englehardt
\end{abstract}

Iron deficiency anemia is the most common nutritional deficiency disease worldwide (Mahan \& Escott-Stump, 2004). Iron deficiency anemia is of major concern especially in women of child bearing age and those who follow a vegetarian diet. The objective of this study was to compare the nutrient and hematological values related to iron status in female university students following a vegetarian versus following a nonvegetarian diet. This study took a cross sectional analysis of 39 female students at California Polytechnic State University (Cal Poly State University) in San Luis Obispo, CA. Of the participants 19 were following a vegetarian diet and 20 were following a nonvegetarian diet. To participate, individuals had to be female, current Cal Poly students, and between the ages of 18 and 22 years old. Those taking vitamin or mineral supplements, medications (including oral contraceptives), smokers, and pregnant women were excluded.

Characteristic, demographic, and anthropometric data were collected through interview, nutrient intake was accessed by averaging three day food records, and hematological parameters were measured. Statistical analysis used nonparametric techniques including the Mann-Whitney Wilcoxon statistical test for demographics and baseline characteristics, the Spearman Rank Correlation analysis and Fisher's Exact statistical test for associations between vegetarians and nonvegetarians. Results found no significant difference in iron intake between vegetarians and nonvegetarians, however nonvegetarians had higher mean intakes of iron at 16.82 (SD 6.36) $\mathrm{mg} /$ day compared to vegetarians at $14.84(\mathrm{SD} 7.10) \mathrm{mg} /$ day $(\mathrm{p}=0.482)$. A similar percentage of vegetarians at 
$66.7 \%(n=8)$ compared to nonvegetarians at $65 \%(n=13)$ were under the Recommended Daily Allowance (18 mg per day for females 19 to 30 years of age) for mean iron consumption. There were slightly more nonvegetarians at $10 \%(\mathrm{n}=2)$ compared to vegetarians at $8.3 \%(\mathrm{n}=1)$ under the Estimated Average Requirement $(8.1 \mathrm{mg} /$ day for females 19 to 30 years of age) for mean iron intake. No significant difference was found for serum iron, serum ferritin, transferrin saturation, and total iron binding capacity between vegetarians and nonvegetarians. Finding revealed serum ferritin, the most common iron status indicator, was lower for vegetarians at 23.16 (SD15.54) ng/mL compared to nonvegetarians at $27.75(\mathrm{SD} 18.01) \mathrm{ng} / \mathrm{mL}(\mathrm{p}=0.47)$. When looking at the stages of iron balance, there was greater percentage of vegetarians with hematological results (serum iron $<40 \mu \mathrm{g} / \mathrm{dL}$, total iron binging capacity of $>410 \mu \mathrm{g} / \mathrm{dL}$, transferrin saturation $<15 \%$, and serum ferritin $<10 \mathrm{ng} / \mathrm{mL}$ ) indicating iron deficiency anemia or stage IV negative iron balance compared to nonvegetarians. There was no significant correlation between iron intake and serum ferritin, however results showed a positive association $(\mathrm{r}=0.28, \mathrm{p}=0.09)$. In conclusion, vegetarian participants are believed to be at higher risk of developing negative iron balance compared to nonvegetarians due to lower iron consumption and lower serum ferritin concentrations. Female university students following a vegetarian diet should be educated on iron deficiency anemia and prevention of iron depletion. 


\section{ACKNOWLEGDMENTS}

An enormous appreciation goes to Dr. Susan Hawk for being my graduate thesis advisor and expanding my knowledge in the field of nutrition. I am also grateful to have Dr. Lisa Nicholson and Dr. Pat Hosegood Martin on my graduate committee team, for their wealth of knowledge and encouragement. I would like to thank Cindi Small the other graduate student researcher for getting this thesis started and the Cal Poly Faculty Support Grant for their financial support. I thank the Cal Poly State University Health Center and all of the women who participated for giving their time and energy to help gather data and complete this project. I would like to acknowledge and thank Dr. Jerome Braun from the University of California at Davis Statistical Laboratory for the assistance with the statistical analysis. Finally, I would like to thank my family and husband, Adam Englehardt, for supporting me through the years and for understanding how much this accomplishment means to me. I appreciate all of your support, thank you. 


\section{TABLE OF CONTENTS}

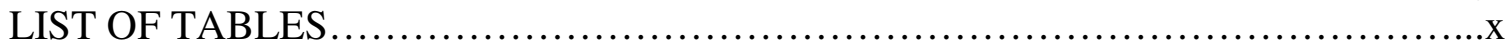

LIST OF FIGURES...................................................................

\section{CHAPTER}

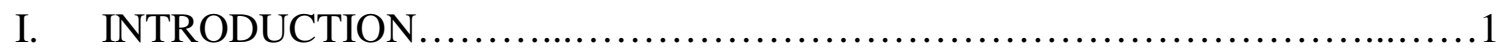

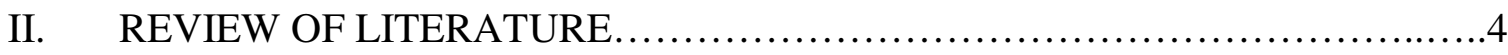

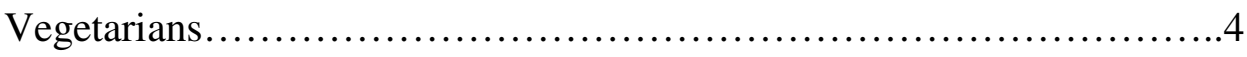

History of Vegetarians........................................5

Reasons for Choosing a Vegetarian Diet.......................6

Reasons for Choosing a Nonvegetarian Diet......................

Characteristics of Vegetarians.................................

Characteristics of Nonvegetarians.............................10

Benefits of the Vegetarian Diet................................11

Concerns for the Vegetarian Diet..............................12

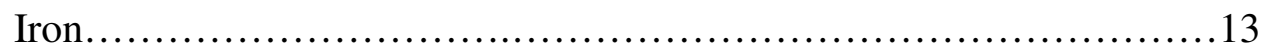

Types of Iron .............................................. 15

Function of Iron........................................... 16

Iron Absorption............................................. 18

Factors Affecting Iron Absorption.............................21

Enhancers of Iron Absorption...........................21

Inhibitors of Iron Absorption............................24

Iron Excretion............................................ 26

Recommended Dietary Allowance of Iron......................27 
Iron Deficiency

Hematological Values Related to Iron Status....................30

Stages of Iron Deficiency.....................................33

Individuals Most Affected.....................................35

Symptoms of Iron Deficiency ................................ 35

Treatment for Iron Deficiency...............................36

Factors Influencing Iron Status................................37

Vegetarians and Iron Status........................................41

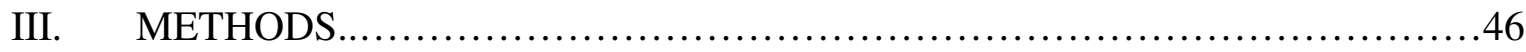

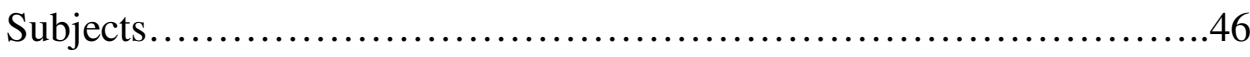

Materials.......................................................... 47

Questionnaire............................................47

Anthropometric Measurements...............................47

Dietary Intake............................................ 47

Hematological Analysis........................................49

Statistical Analysis.................................................... 49

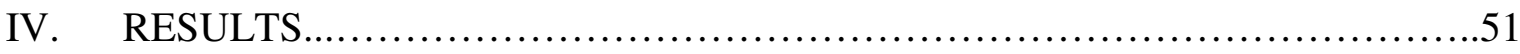

Subject Characteristics and Demographic.............................51

Dietary Intake.................................................... 52

Dietary Reference Intake of Iron.............................54

Hematological Analysis............................................55

Serum Ferritin............................................56

Iron Balance................................................57 
Relationship Among Dietary Intakes and/or Hematological Analysis.....59

V. DISCUSSION....................................................... 62

Subject Characteristics and Demographic..........................62

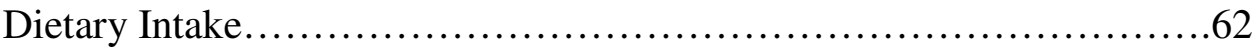

Hematological Analysis........................................64

Relationship Among Dietary Intakes and/or Hematological Analysis.....65

Iron Intake and Serum Ferritin.................................67

Limitations.................................................69

Conclusion...................................................... 70

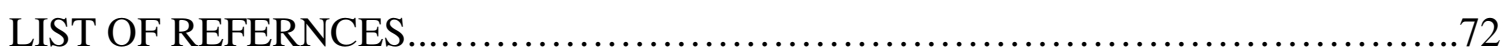

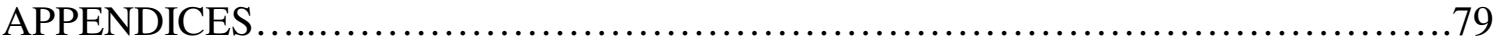

A. Recruitment Flier Posted in Community.............................8 80

B. Research Project Informed Consent.................................82

C. Research Project Background Questionnaire...........................84

D. Food Frequency Questionnaire................................... 87

E. Food Record Instructions.........................................90

F. Food Record Reference List...................................94

G. Blood Draw Instructions .......................................99 


\section{LIST OF TABLES}

Table

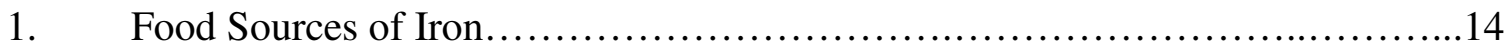

2. The Relative Proportions of the Major Categories of Iron in Men and Women....................................................... 17

3. Lists of the Major Functions of Iron in the Body........................... 19

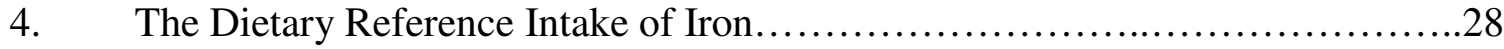

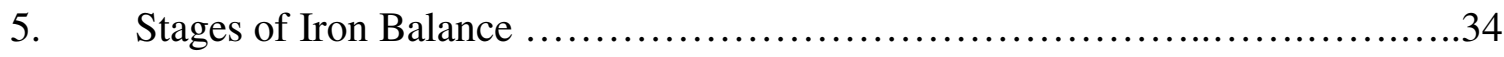

6. Demographics of Participants........................................52

7. Selected Daily Nutrient Intakes Vegetarians and Nonvegetarians................53

8. The Percentage of Vegetarians and Nonvegetarians Below Recommended Iron Intake Levels................................................... 55

9. Selected Hematological Measure for Vegetarians and Nonvegetarians............56

10. The Percentage of Vegetarians and Nonvegetarians Above and Below Cut-off Points for Selected Iron Status Indices..............................58

11. Correlations between Dietary Intakes and/or Hematological Values...............60

12. Results of Similar Studies on Iron Intake and Serum Ferritin Values of Vegetarians and Nonvegetarians 


\section{LIST OF FIGURES}

$\begin{array}{ll}\text { Figures } & \text { Page }\end{array}$

1. Frequency Distribution of Serum Ferritin in

Vegetarians and Nonvegetarians........................................5 


\section{CHAPTER 1}

\section{Introduction}

Iron deficiency anemia is the most common nutritional deficiency disease worldwide (Mahan \& Escott-Stump, 2004). It has been estimated that in the United States, impaired iron status occurs in $1 \%$ to $6 \%$ of the general population (Messina \& Messina, 1996). Iron deficiency anemia represents the end point of a long period of iron depletion. In the United States, iron deficiency anemia is most prevalent among children and women of child bearing age (Mahan \& Escott-Stump, 2004). In general, females have an inferior iron status compared to males, regardless of dietary practice (Shaw, Chin, \& Pan, 1995). Roughly $5 \%$ to $14 \%$ of women in the United States aged 15 to 44 years of age have impaired iron status (Messina \& Messina, 1996). One study reported that younger women had the highest risk of developing early stages of iron depletion, which was found in $5 \%$ of women aged 50 to 79 and $16 \%$ of women aged 20 to 49 years (Brussaard, Brants, Bouman, \& Lowik, 1997). Marginal iron status has been found to be a potential problem in women, especially in those consuming a vegan or vegetarian diet (Haddad, Berk, Kettering, Hubbard, \& Peters, 1999). This is of concern given that iron is stored and needed for cellular metabolism (Mahan \& Escott-Stump, 2004). Iron is found in two forms: nonheme iron found in plant sources and heme iron found in animal and plant sources of food. The most important dietary factors influencing one's iron status are the type of iron and those factors affecting its bioavailability (Brussaard et al., 1997).

In 2005, the United States Department of Agriculture (USDA) published the Dietary Guidelines for Americans giving recommendations for women of childbearing age to eat foods high in heme-iron and/or consume iron-rich plant foods or iron-fortified foods with 
an enhancer of iron absorption, such as vitamin C-rich foods to prevent iron deficiency in this population (United States Department of Health and Human Services (U. S. DHHS), 2005). Vegetarian diets usually contain no meat and animal products. Women of childbearing age that follow this type of diet may be at particular risk of nutrient deficiencies (U. S. DHHS, 2005). In one study, vegetarians had depleted iron stores compared to nonvegetarians, suggesting an increased risk of impaired iron status when diets are limited in red meat (Donovan \& Gibson, 1995).

A population that may be at risk for poor iron status are the female vegetarian students of child-bearing age at Cal Poly State University. Previous research studies examined individuals consuming a vegetarian diet of all ages and gender, however the criteria to participate has been conflicting. The Review of Literature discusses many factors known to affect iron status in individuals. A few of the conflicting factors include the use of vitamin and/or mineral supplements, medications such as oral contraceptives, and how strictly the vegetarian diet is defined. There is a need for research controlling for these conflicting factors when looking at vegetarian's iron status to accurately assess this population.

To summarize, this study was initiated in 2005 to examine the iron status of vegetarian and nonvegetarian females at Cal Poly State University. Nutrient intake was assessed by averaging three day food records. Hematological parameters were also measured for each participant. To participate, individuals had to be female, current Cal Poly students, and between the ages of 18 and 22 years old. Those taking vitamin or mineral supplements, medications (including oral contraceptives), smokers, and pregnant women were excluded. The vegetarian participants did not include meat or fish in their 
diet for approximately one year prior to the study. The objective of this study was to compare the nutrient and hematological values related to iron status in female university students following a vegetarian versus nonvegetarian diet. The researcher hypothesized that there was a significant difference between iron intake and hematological values related to iron status including hemoglobin, serum iron, serum ferritin, transferrin saturation, and total iron binding between vegetarian and nonvegetarian female students studied. The accompanying null hypothesis was that there is no significant difference between iron intake and hematological values related to iron status between vegetarian and nonvegetarians female students studied.

As discussed, females of child-bearing age consuming a diet limited in animal protein (heme iron), which includes the vegetarian diet, may be at risk for poor iron status. Therefore, this study took place to research the effects of a vegetarian diet on iron status in female Cal Poly State University students. An overview of the vegetarian diet and the importance of iron are discusses in the Review of Literature. 


\title{
CHAPTER 2
}

\author{
Review of Literature \\ Vegetarians
}

According to the Dietary Guidelines for Americans 2005, there are several vegetarian categories, all of which avoid meat and/or animal products (U. S. DHHS, 2005). The vegan diet includes only plant foods including, fruits, vegetables, legumes (dried beans and peas), grains, seeds, and nuts. The lacto-vegetarian diet includes plant foods plus dairy products, and the lacto-ovo-vegetarian diet includes plant foods, dairy products plus eggs. The semi-vegetarian diet does not include red meat but does include chicken or fish along with plant foods, dairy products, and eggs (U. S. DHHS, 2005).

Even though the Dietary Guidelines for American have specifically defined categories of vegetarianism, many research studies have used slightly different criteria. Vegans have been defined as those who consume plant based diet for at least six months (Larsson \& Johansson, 2002), and those who consume dairy products no more than six times a year (Due, Sinclair, Mann, Turner, \& Ball, 2000). Lacto-ovo-vegetarians have been defined as those who consume milk, dairy products, and eggs but, allow poultry and fish less than once every fifteen days (Meirelles, Veiga, \& Soares, 2001) or once a week (Wilson \& Ball, 1999). Other studies allow lacto-ovo-vegetarians to eat meat less than six times per year (Due et al., 2000), or fish products in smaller amount than the nonvegetarians (Thane \& Bates, 2000). One study generalized vegetarians as those who eat meat or fish less than once a week (Cade, Burley, \& Greenwood, 2004), red meat no more than once a month and chicken or fish no more than once a week (Alexander, Ball, \& Mann, 1994; Ball \& Bartlett, 1999). Nonvegetarians or omnivores have been defined 
as people eating food of both plant and animal origin their entire life (Larsson \& Johansson, 2002). Studies used individuals who ate meat once a week (Meirelles et al., 2001) or those who consumed a certain amount of meat per day, as a definition of a nonvegetarian (Due et al., 2000). Thus, the definitions of vegetarians and nonvegetarians are not consistent and must be reviewed.

\section{History of Vegetarians}

Throughout history there have numerous religions and beliefs that support vegetarianism including Buddhism, Seventh Day Adventists, many Hindus, and some Roman Catholic groups (The Vegetarian Society, n.d.). According to the The Dietitian's Guide to Vegetarian Diets Issues and Applications (1996), the term "vegetarian" was not coined until the mid 1800's. However, the diet dates back to the sixth century BC from the Greek philosopher Pythagoras. He was called the father of vegetarianism, encouraging meatless eating among his followers and stating it was the most natural and healthful way of eating (Messina \& Messina, 1996). The nineteenth century showed the birth of the true vegetarian movement related to the church. In the 1800's Reverend William Cowherd, founder of the Bible Christian Church of England, embraced the vegetarian diet as prescribed by God in the book of Genesis (Messina \& Messina, 1996). Sylvester Graham was another member of this church who toured the United States

lecturing on the evils of meat. In the mid 1840's the Bible Christians established the Vegetarian Society of Great Britain and the American Vegetarian Society soon followed (Messina \& Messina, 1996). The next large movement was through the Seventh-day Adventist Church by the founder Ellen White in the 1840's. John Harvey Kellogg was a head member of the church and went on to commercially produce cereal, peanut butter, 
and soy products (Messina \& Messina, 1996). It was estimated in 1943 that $2 \%$ of Americans were consuming a vegetarian diet. In the 1970's a book by Frances Moore Lappe called the Diet for a Small Planet discussed adverse effects of meat production on the planet (Messina \& Messina, 1996). In 1975, Peter Singer led an animal liberation group forming the people for the Ethical Treatment of Animals. The number of vegetarians doubled between 1985-1992, with an estimate of 12 million Americans calling themselves vegetarians (Messina \& Messina, 1996). According to the U.S Census Bureau (2000) in 1992 there were approxamently 255 million Americans; therefore, an estimated $4.7 \%$ of Americans were consuming a vegetarian diet.

Reasons for Choosing a Vegetarian Diet

Individuals may choose to follow a vegetarian diet due to philosophical, religious, ecological, animal welfare, environmental, personal health, or weight concerns (Mahan \& Escott-Stump, 2004). Some women believe meat is not healthful because it may contain hormones, antibiotics, additives, and environmental contaminants (Barr \& Chapman, 2002). One study stated that vegetarians believe meat causes disease and other health problems (Lea \& Worsley, 2001). It has been reported that vegetarians in France believe their diet is an answer to nutritional and medical problems, and it is a way to return to a more natural life. However, the primary reason for the rejection of meat is because of the cruelty to animals and a crusade for health (Leblanc, Yoon, Kombadjian, \& Verger, 2000). Disease prevention also played a role in diet choices of female vegetarians studied. A study found vegetarians were more likely to consider cancer, osteoporosis, food allergies and intolerances, and avoid foods because of their salt content than nonvegetarians (Bedford \& Barr, 2005). 


\section{Reasons for Choosing a Nonvegetarian Diet}

Individuals may choose to follow a nonvegetarian diet due to concerns about lack of iron, protein (Lea \& Worsley, 2001), calcium, and vitamin B12 (Barr \& Chapman, 2002). Participants reported that the difficulties with vegetarian diets include health concerns or not feeling healthy, missing the taste or enjoyment of eating meat, not knowing what to eat instead of meat, social concerns about vegetarianism, and social influence against vegetarianism (Lea \& Worsley, 2001). For these reasons, as well as changes in living situations, former vegetarians have resumed eating a nonvegetarian diet (Barr \& Chapman, 2002). For those choosing between a vegetarian and nonvegetarian diet, some have stated that the frequency of meat consumption is determined by health concerns, appropriateness of meat with the meal, the number of vegetarian friends, and whether they believe meat is unhealthy or a necessary dietary component (Lea \& Worsley, 2001).

\section{Characteristics of Vegetarians}

There are numerous research studies involving vegetarians throughout the world. A study in Minnesota reported 5.8\% of 4,746 adolescents were vegetarian (Perry, McGuire, Neumark-Sztainer, \& Story, 2002). Another study found a similar 5.8\% of 1,817 individuals from British Columbia reported being vegetarian, however they did not adhere rigidly to a flesh free diet. It was determined that if a strict definition of a vegetarian was used in this study the prevalence of vegetarians would be less than $1.5 \%$ (Bedford \& Barr, 2005). Of the self reported vegetarians from British Columbia, 74.9\% consumed fish and/or seafood, $57.6 \%$ consumed poultry, $22.4 \%$ consumed red meat, 97.3\% consumed dairy products and $92.3 \%$ consumed eggs (Bedford \& Barr, 2005). A similar survey on vegetarians found that $62 \%$ reported eating chicken and/or fish and 
$32 \%$ ate eggs and/or dairy products (Perry et al., 2002). A European study found 33\% of 35,372 women had defined themselves as vegetarian, but based on a food frequency questionnaire only $18 \%$ were actually vegetarian (Cade et al., 2004). Thus, it is important for researchers to clarify the meaning of vegetarianism and use strict criteria when recruiting vegetarians from a population. A study using strict criteria on 90 selfdefined vegetarians placed each into the following groups: $7 \%$ vegans, $12 \%$ lactovegetarians, 24\% lacto-ovo-vegetarians, $41 \%$ pesco-vegetarians (consumes fish), and $16 \%$ pollo-pesco (consumes fish and chicken) vegetarians (Barr \& Chapman, 2002). Researchers looking at diet characteristics of Seventh-day Adventists in California found $25.5 \%$ of participants were vegetarians, $21.2 \%$ were semi-vegetarians, and $49.2 \%$ were non-vegetarians (Fraser, 1999). This study reveals that even in a culture with many individuals following a vegetarian diet, there are still fewer vegetarians compared to nonvegetarians.

Vegetarians consume a varying amount of food and nutrients. Common foods in the vegetarian diet include various nuts, oil, seeds, soy, whole grain products, and grain sprouts (Krajcovicova-Kudlackova et al., 2003). On average vegetarians consumed a higher mean intake of cereal, pasta, citrus fruits, fruit juices, apples, melons, berries, starchy vegetables, dark green and yellow vegetables, tomatoes, legumes, fruit, lettuce, beans, green beans, rice, bananas, reduced fat milk, yogurt, poultry and fish compared to nonvegetarians. However, vegetarians consumed lower mean intake of baked goods, dry snacks, fried potatoes, processed meats, nut and seeds, soft drinks, coffee, doughnuts, eggs, cheese, chocolate, sweets, and natural juices compared to nonvegetarians (Fraser, 1999; Ledikwe et al., 2006; Meirelles et al., 2001). Based on diet history interviews it 
was reported that vegans had higher mean intakes of rice, vegetables, legumes, and wheat bread, with lower intakes of cake, cookies, candy, and chocolate than nonvegetarians (Larsson \& Johansson, 2002). As for alcohol intake in a Food Frequency Questionnaire and through Food Records, vegetarians were less likely to drink alcohol compared to nonvegetarians (Cade et al., 2004; Kandiah, 2002). Based on a seven day food record, vegetarians' mean nutrient intake tends to be higher in percent energy from carbohydrates and lower in percent energy from proteins and fats (Davey, Spencer, Appleby, Allen, Knoex, \& Key, 2003). Other nutrients include higher mean intakes of fiber, magnesium, and potassium, with lower intakes of thiamin, folate, vitamin B6, vitamin $\mathrm{C}$, and iron (Bedford \& Barr, 2005; Cade et al., 2004; Huang et al., 1999; Wilson \& Ball, 1999).

Characteristic data revealed vegetarians to be younger in age (Bedford \& Barr, 2005; Cade et al., 2004; Davey et al., 2003). The mean age ranges of Australian vegetarian women were between 18.9 to 31.7 years (Ball \& Bartlett, 1999). Age probably explains some of the differences in lifestyle and dietary choices observed between diet groups (Davey et al., 2003). As for gender, vegetarians were more likely to be female (Bedford \& Barr, 2005; Davey et al., 2003; Perry et al., 2002). Vegetarians tended to spend less total time on regular physical activity, but exercised with more frequency and duration compared to nonvegetarians (Meirelles et al., 2001). In France, it was reported that $89 \%$ of the vegetarian population studied were physical active on a daily bases (Leblanc et al., 2000). Body mass index (BMI) was found to be lower in vegans and vegetarians (Due et al., 2000; Haddad et al., 1999). However, some studies found no significant difference between diet groups (Ball \& Bartlett, 1999; Larsson \& Johansson, 2002). Based on the BMI, one study found vegetarians were more overweight (Meirelles et al., 2001), but 
have a lower range BMI compared to nonvegetarians (Ball \& Bartlett, 1999; Davey et al., 2003; Huang, Lin, Cheng, \& Su, 1999; Kandiah, 2002). None of the studies reviewed showed vegetarians as having higher BMI's than nonvegetarians.

Compared to their counterparts, vegetarians and vegans were more likely to be single (Davey et al., 2003), less likely to have children living in the home, and more likely to be white (Bedford \& Barr, 2005; Perry et al., 2002). There were also, conflicting data with socio-economic status among vegetarians. Vegetarians in British Columbia were more likely to be low income (Bedford \& Barr, 2005), while women in the United Kingdom tended to be in the higher socio-economic groups (Greenwood, Cade, Draper, Barrett, Calvert, \& Greenhalgh, 2000). With respect to education, it was reported that vegetarians and health conscious groups were better educated (Davey et al., 2003; Greenwood et al., 2000). Studies also reported the length of time vegetarian and vegan participants followed their diet. Vegetarians had followed their diet for a mean of almost fifteen years, where former vegetarians had followed the diet for an average of 3.3 years before resuming a nonvegetarian diet (Barr \& Chapman, 2002). Other studies report that the vegetarian participants had followed a vegetarian diet for a mean of 3.5 years (Huang et al., 1999) and 2.8 years, where vegans had followed the diet for a mean of 1.7 years (Larsson \& Johansson, 2002). Thus, the more restrictive diets are followed for a shorter period of time.

\section{Characteristics of Nonvegetarians}

In comparison, nonvegetarians tended to be slightly older in age, have a higher body mass index, and less likely to have a degree compared to vegetarians (Cade et al., 2004). Based on a Food Frequency Questionnaire, nonvegetarians were less likely to use full-fat 
milk, had lower servings of fruits, vegetable, carbohydrates, and percentage energy from carbohydrates. Nutrient intakes in nonvegetarians were lower in fiber, vitamin C, folate, iron and calcium, with highest intake in energy from protein and fat, vitamin A, and zinc (Cade et al., 2004). Donovan and Gibson (1995) also found from weighted food records higher mean intake of heme iron, meat, poultry, and fish compared to vegetarians. The discrepancy of iron intake is discussed further in the Review of Literature.

\section{Benefits of the Vegetarian Diet}

Many health benefits are associated with the vegetarian diet. Adolescent vegetarians were more likely than nonvegetarian adolescents to meet the Healthy People 2010 Objectives (Perry et al., 2002). One objective included in the Healthy People 2010: Reduce iron deficiency among young children \& females of childbearing age (United States Department of Health and Human Services, 2000). In terms of nutrients, vegetarian-like diets, have been found to be higher in vitamin A, vitamin $\mathrm{C}$, vitamin $\mathrm{B}$, folate, iron, calcium, and potassium based on 24-hour Food Recalls (Ledikwe et al., 2006). Higher in dietary fiber based on a Food Frequency Questionnaires and 12-day Food Records (Ball \& Bartlett, 1999; Haddad et al., 1999). Higher in daily serving of vegetables with vegetarian-like diet consuming five or more servings of fruits and vegetables a day, based on self-reported date (Perry et al., 2002). Also, a diet with richer sources of antioxidants compared to nonvegetarian diets discovered through surveys (Krajcovicova-Kudlackova et al., 2003). Through the use of Food Records the vegetarian diet tended to avoid unhealthy foods with lower intake of total fat, cholesterol (Meirelles et al., 2001), and saturated fat (Ball \& Bartlett, 1999; Haddad et al., 1999). Self reported 
data also indicated those on a vegetarian diet avoided fast food and regular sodas (Perry et al., 2002).

Individuals consuming a vegetarian diet reported less illness (Cade et al., 2004). They also had decreased cancer and overall mortality (Frentzel-Beyme \& Chang-Claude, 1994). A study on Seventh-day Adventist women found they lived an average of 2.52 years longer than nonvegetarians (Fraser, 1999). Other findings revealed that vegetarians on the diet for more than 10.6 years had a $24 \%$ reduction in mortality for ischemic heart disease (Key et al., 1998). Cancers of the colon and prostate were also significantly less likely, with an increased risk of colon cancer of $88 \%$ in nonvegetarians, when eating both red and white meat (Fraser, 1999). Vegetarians had lower risk of bladder cancer, breast cancer, diabetes mellitus, hypertension, arthritis, and rheumatoid arthritis (Fraser, 1999). This study, which used a Food Frequency Questionnaire method, noted that the decreased disease risk could be due to the lower intake of meat, but it is possible that it could be due to the increased consumption of fruits, vegetables, and nuts (Fraser, 1999). According to the Dietary Guidelines for Americans 2005, vegetarians of all types can achieve the recommended nutrient intakes through a careful selection of foods (U. S. DHHS, 2005). Concerns for the Vegetarian Diet

Researchers suggest that the beneficial effects expected from vegetarian diets should be evaluated in light of potential harm which may arise from iron and vitamin B12 deficiencies (Obeid, Geisel, Schorr, Hubner, \& Herrmann, 2002). The vegetarian diet tends to be lower than the average requirements for riboflavin, vitamin B12 (Perry et al., 2002) vitamin D, calcium, selenium (Larsson \& Johansson, 2002), monounsaturated fat (Haddad et al., 1999), and protein (Ball \& Bartlett, 1999). It has been estimated that only 
$17 \%$ of vegetarians reached the recommended allowance for protein and $83 \%$ ate less then two thirds of the recommended allowance of calcium (Meirelles et al., 2001). Vegans also had the lowest intakes of retinol, vitamin B12, vitamin D, calcium, and zinc compared to lacto-ovo-vegetarians (Davey et al., 2003). Some authors stated that an overly restricted or poorly selected vegetarian diet can result in significant malnutrition (Mahan \& Escott-Stump, 2004). Therefore, researchers believe it is important for vegetarians to pay special attention to consumption of energy, protein, iron, zinc, vitamin B12, calcium, and vitamin D to ensure adequate intake (U. S. DHHS, 2005).

\section{Iron}

Dietary iron is obtainable from a variety of sources including plants such as fruits and vegetables, fortified breads and grain products, as well as animal source foods including meat and poultry (Institute of Medicine of the National Academies (IOM), 2004). The food sources with high amounts of iron which include canned clams, oysters, soybeans, pumpkin and squash seeds, white beans, blackstrap molasses, lentils, spinach, and beef are shown in Table 1 (U. S. DHHS, 2005). One unusual source or iron is from the use of an old fashioned iron skillet. The iron in the skillet leaches iron in to the cooked foods (Mahan \& Escott-Stump, 2004). Another source is from the iron fortified cereals, flours, and bread, fortification of which began in 1941. Fortification has aided in increasing total dietary iron intake, as well as a reducing iron deficiency anemia in the United States (Mahan \& Escott-Stump, 2004; Whittaker, Tufaro, \& Rader, 2001). According to Hallberg and Hulthen (2000), it is important to consider nonheme iron fortification in meals. Manufacturers are currently fortifying read-to-eat cereals with levels of iron ranging from $8 \%$ to $100 \%$ of the Daily Value, based on the Recommended Daily Intake 
Table 1. Food Sources of Iron

\begin{tabular}{|c|c|}
\hline Food in Standard Amount & Iron $(\mathrm{mg})$ \\
\hline Clams: canned, drained, $3 \mathrm{oz}$ & 23.8 \\
\hline Fortified ready-to-eat cereal (various): $\sim 1 \mathrm{oz}$ & $1.8-21.1$ \\
\hline Oysters: eastern, wild, cooked, moist heat, $3 \mathrm{oz}$ & $5.2-9.9$ \\
\hline Fortified instant cooked cereal (various): 1 packet & $4.9-8.1$ \\
\hline Soybeans: mature, cooked, $1 / 2$ cup & 4.4 \\
\hline Pumpkin and squash seed kernels: roasted, $1 \mathrm{oz}$ & 4.2 \\
\hline White bean: canned, $1 / 2$ cup & 3.9 \\
\hline Blackstrap molasses: 1 Tbsp & 3.5 \\
\hline Lentils: cooked, $1 / 2$ cup & 3.3 \\
\hline Spinach: cooked from fresh, $1 / 2$ cup & 3.2 \\
\hline Beef: chuck, blade roast, lean, cooked, $3 \mathrm{oz}$ & 3.1 \\
\hline Beef: bottom round, lean, all grade, cooked, 3oz & 2.8 \\
\hline Kidney beans: cooked, $1 / 2$ cup & 2.6 \\
\hline Sardines: canned in oil, drained, $3 \mathrm{oz}$ & 2.5 \\
\hline Chickpeas: cooked, $1 / 2$ cup & 2.4 \\
\hline Prune juice: $3 / 4$ cup & 2.3 \\
\hline Shrimp: canned, $3 \mathrm{oz}$ & 2.3 \\
\hline Ground beef: $15 \%$ fat, cooked, $3 \mathrm{oz}$ & 2.2 \\
\hline
\end{tabular}

Modified From U. S. DHHS, 2005.

of $18 \mathrm{mg}$ of iron (Whittaker et al., 2001). Whittaker et al. (2001) analyzed breakfast cereals finding varied amounts in their iron content from $80 \%$ to $190 \%$ of the labeled value. In the United Kingdom it is mandatory to fortify all wheat flour with iron (British Nutrition Foundation, 2008). The benefits of fortification were apparent among British adolescent girls, where iron intake is more prevalent do to high consumption of breakfast cereals (Thane, Bates, \& Prentice, 2003). Iron-fortified infant formula in Europe has also positively influenced iron status in infants (Male et al., 2001). Other food vehicles used in iron fortification programs for general population include wheat, flour, sugar, and salt (Davidsson, Walczyk, Zavaleta, \& Hurrell, 2001). In Peru, foods provided in the school meal programs are used as a vehicle to prevent iron deficiency anemia in children (Davidsson, Walczyk, Zavaleta, \& Hurrell, 2001). 
Cereals provide the main source of dietary iron for vegetarians and nonvegetarians (Wilson \& Ball, 1999). An Australian study found that vegetarians obtained $29.8 \%$ or their iron from cereal and cereal products, $15 \%$ from breakfast cereals, and $6.4 \%$ from fruit. Nonvegetarian participants obtained $27.7 \%$ of their iron form cereal and cereal products, $16.1 \%$ from meat and meat products, $16 \%$ vegetables, $15 \%$ breakfast cereals, and 4.6\% from nonalcoholic beverages (Ball \& Bartlett, 1999). Another study examining total iron intake of the vegetarian and nonvegetarian diet found no difference between the two even though the vegetarian diet obtained $32.9 \%$ of their iron from vegetables, $17.5 \%$ from soybean products, $1.9 \%$ from fruits, $0.2 \%$ from dairy, and $2.4 \%$ from other. In contrast, the nonvegetarians obtained 33.5\% of its iron from animal products such as meat, fish, and eggs, $15.8 \%$ from vegetables, $8.6 \%$ from soybean products, $4.9 \%$ from fruits, $0.3 \%$ from dairy, and $0.5 \%$ from other (Shaw et al., 1995). It is estimated that plant foods contribute $90 \%$ of the dietary iron for lacto-ovo-vegetarians, $84 \%$ for the semi-vegetarians, and $82 \%$ for the nonvegetarians (Donovan \& Gibson, 1995). Types of Iron

There are two forms of dietary iron. Heme iron is found in animal sources of food including meat, poultry, and fish (IOM, 2004; U. S. DHHS, 2005). The other form is nonheme iron and can also be found in meat, poultry, and fish as well as eggs, grains, vegetables, and fruits (U. S. DHHS, 2005). In a mixed diet, meat and meat products account for $40 \%$ of the heme and $60 \%$ of the nonheme iron. Nonmeat products contain $100 \%$ of nonheme iron (Tseng, Chakraborty, Robinson, Mendez, \& Kohlmeier, 1997). When calculating the heme content of meat, researchers estimate that the heme content of pork is $35 \%$, with beef, lamb, and chicken at 55\%. Not all meat iron is in the heme form 
and not all heme iron is available for absorption. Therefore, there is no agreement as to how to calculate heme iron content of foods. Researchers usually use an estimate of $40 \%$ to calculate the heme content of all meats (Burgess, Hackett, Kirby, Maxwell, \& Nathan, 2001; Wells, Haub, Fluckey, Williams, Chernoff, \& Campbell, 2003). One study calculated the heme content of their participants following a nonvegetarian diet and found that heme iron accounted for only $10 \%$ of the iron consumed (Alexander et al., 1994). Other studies have found that in the nonvegetarian diet, meat provided $33 \%$ of the iron in which $13 \%$ to $16 \%$ was in the heme form, with the rest of iron at $67 \%$ from plant sources and fish (Burgess et al., 2001). Heme iron intake of French vegetarians accounted for 0.2 mg per day in the lacto-ovo-vegetarians, and none in the lacto-vegetarians and vegans $(\mathrm{p}<0.01)$ (Leblanc et al., 2000). Consumption of iron derived from the different sources of food is important because heme and nonheme iron have different bioavailability (Mahan \& Escott-Stump, 2004), which is discussed later in the Review of Literature.

\section{Function of Iron}

There are two major categories of iron in the human body: functional and storage iron. The first type is called functional iron, found in hemoglobin, myoglobin, and enzymes. Hemoglobin is an iron-containing protein in the red blood cells, and myoglobin is a heme-containing protein that serves as an oxygen reservoir within the muscles and enzymes (Mahan \& Escott-Stump, 2004). As for storage iron, ferritin and hemosiderin store iron, while transferrin serves as an iron transport protein in the blood (Mahan \& Escott-Stump, 2004). The concentration of iron in the body is approximately 30-40 mg per kg of body weight, which may vary according to age and gender (Beard, 2001). The body's iron storage iron pool can contain as much as 2-3 grams of iron, in 
which $30 \%$ is stored in the liver and another $30 \%$ in the bone marrow (Beard, 2001). The rest of the iron is stored in the spleen and muscles (Beard, 2001; Mahan \& Escott-Stump, 2004). The proportions and percentage of the two major categories of iron in men and women are shown in Table 2.

Table 2. The Relative Proportions of the Major Categories of Iron in Men and Women

\begin{tabular}{|l|c|c|c|c|}
\hline & \multicolumn{2}{|c|}{ Men: Iron Content } & \multicolumn{2}{c|}{ Women: Iron Content } \\
\hline \multicolumn{1}{|c|}{ Iron Type } & $\mathrm{Mg}$ & $\%$ & $\mathrm{Mg}$ & $\%$ \\
\hline \multicolumn{1}{|c|}{ Functional } & & & & \\
\hline Hemoglobin & 2300 & 64 & 1700 & 73 \\
\hline Myoglobin & 320 & 9 & 180 & 8 \\
\hline Heme enzymes & 80 & 2 & 60 & 3 \\
\hline Nonheme enzymes & 100 & 3 & 80 & $3+$ \\
\hline \multicolumn{1}{|c|}{ Storage } & & & & \\
\hline Ferritin & 540 & 15 & 200 & 9 \\
\hline Hemosiderin & 230 & 6 & 100 & 4 \\
\hline Transferrin & 5 & $<1$ & 4 & $<1$ \\
\hline \multicolumn{1}{|c|}{ Total } & $3575(3.6 \mathrm{~g})$ & 100 & $2314(2.3 \mathrm{~g})$ & 100 \\
\hline
\end{tabular}

Mahan \& Escott-Stump, 2004.

Of the two major categories of iron, functional iron is important for iron metabolism.

It aids in red blood cell function, myoglobin activity, and enzymatic activity. Iron plays a role in the binding and transport of oxygen through the red blood cells (Beard, 2001; Syed, Sargent, Farnaud, \& Evens, 2006). For each hemoglobin molecule, approximately 300 million in each red blood cell, there are four globular proteins containing one heme group. Each heme group has an iron atom, which can bind oxygen, nitrogen, and sulfur atoms (Beard, 2001). The hemoglobin molecule is responsible for bringing oxygen to the lungs and releasing oxygen in the tissues. It can then pick up carbon dioxide from the tissues and releases it into the lungs (Mahan \& Escott-Stump, 2004). Myoglobin acts as the facilitator of oxygen diffusion in the tissues (Beard, 2001). In iron deficiency anemia, an individual's homeostasis is interrupted with respect to oxygen transport, leading to 
decreased maximal aerobic capacity (Beard, 2001). Heme and nonheme iron containing enzymes, are involved in the electron transfer reaction production of energy (Beard, 2001; Mahan \& Escott-Stump, 2004). The cytochromes containing heme groups, present in most cells, function "to reduce ferrous +3 iron to ferric +2 iron with the acceptance of electrons" (Beard, 2001). Cytochrome P-450 can transform water insoluble drugs and organic molecules in the liver into more water soluble molecules that can be secreted in the bile and eliminated (Mahan \& Escott-Stump, 2004). Other functions include sulfur enzymes that can act as electron carriers via iron bound to sulfur atoms and cysteine side chains (Beard, 2001) and ribonucleotide reductase enzymes which are involved in DNA synthesis (Syed et al., 2006; Mahan \& Escott-Stump, 2004). One researcher points out that the activity of many of these enzymes decrease during iron deficiency (Beard, 2001). Major functions of iron metabolism, transport, and storage are shown in Table 3.

\section{Iron Absorption}

Heme iron, unlike nonheme iron, is highly bioavailable and readily absorbed (Syed et al., 2006). Heme iron has an intact ferroporphyrin ring, which is absorbed across the brush border membrane of the duodenal and proximal jejunum enterocytes (Frazer \& Anderson, 2005; Mahan \& Escott-Stump, 2004; Syed et al., 2006). After the heme enters the cytosol, the ferrous iron is enzymatically removed from the ferroporphyrin complex, by heme oxygenasis (Mahan \& Escott-Stump, 2004; Syed et al., 2006). With respect to nonheme iron absorption, it also occurs in the duodenum and proximal jejunum. Nonheme iron is absorbed in a soluble and ionized form to also be transferred across the brush boarder mucosa cells, via a divalent metal transporter 1 (Frazer \& Anderson, 2005). 
Table 3. Lists of the Major Functions of Iron in the Body

\begin{tabular}{|l|l|}
\hline \multicolumn{1}{|c|}{ Iron Type } & \multicolumn{1}{c|}{ Function } \\
\hline Metabolic Proteins & \\
\hline Heme Proteins & Oxygen transport from lung to tissue \\
\hline Hemoglobin & Transport and storage of oxygen in muscle \\
\hline Myoglobin & \\
\hline Heme Enzymes: & Electron transport \\
\hline Cytochromes & Oxidative degradation of drugs \\
\hline Cytochrome P-450 & $\begin{array}{l}\text { Conversion of hydrogen peroxide } \\
\text { to oxygen and water }\end{array}$ \\
\hline Catalase & \\
\hline Nonheme Enzymes: & Oxidative metabolism \\
\hline Iron-Sulfur \& Metalloproteins & \\
\hline Iron Dependent Enzymes: & Oxidation of tryptophan \\
\hline Tryptophan pyrolase & \\
\hline Transport and Storage Proteins & Transport of iron and other materials \\
\hline Transferrin & Storage \\
\hline Ferritin & Storage (more iron and is insoluble) \\
\hline Hemosiderin & \\
\hline
\end{tabular}

Modified From Mahan \& Escott-Stump, 2004.

For this to occur, acid in gastric secretion and ferric reductase enzymes have to enhance the solubility and change the iron to the ionic state. Iron changes from ferric iron +3 (environmental iron with low solubility) to ferrous iron +2 (Frazer \& Anderson, 2005; Syed et al., 2006). The ferrous state, or reduced from, is preferred in the body. However, some ferric iron can also be transferred across brush border to the basolateral membrane. Ferrous iron is more soluble at $\mathrm{pH} 7$ in the stomach and remains available for absorption (Mahan \& Escott-Stump, 2004).

Ferrous or free iron, originally from heme and nonheme iron ions, is carried from the brush border cells to the basolateral membrane lining through an auxiliary ferroxidase activity. This is mediated by the iron transport protein, ferroportin 1 (Frazer \& Anderson, 2005; Syed et al., 2006). The total iron binding capacity (TIBC) of transferrin, another iron transport protein, stimulates the absorbing cells to transport iron from the basolateral 
membrane lining to the sites for utilization or storage (Syed et al., 2006). If iron is not needed for utilization it is incorporated into ferritin or hemosiderin, iron storage molecules (Frazer \& Anderson, 2005). Ferritin is capable of binding up to 4,600 ferric iron ions for storage and will return iron to the lumen when needed (Syed et al., 2006). When needed, iron ions can then move into the blood through an active transport mechanism which requires energy and circulates bound to transferrin in the ferric ion form (Fairweather-Tait, 2004; Mahan \& Escott-Stump, 2004). In normal individuals the transferrin saturation ranges from $25-40 \%$ in the blood (Syed et al., 2006). However, with iron deficiency anemia transferrin saturation can be as high as 50\% (Mahan \& Escott-Stump, 2004). The increase in transferrin saturation means that more transferrin circulates in the blood for cells to absorb, which aids in correcting iron deficiency anemia. Transferrin receptors on cells signal transferrin and assist in iron uptake into cells (Syed et al., 2006). The body increases or decreases transferrin receptors to regulate the amount of iron entering the blood, through a recently discovered iron regulatory hormone hepcidin (Syed et al., 2006; Frazer \& Anderson, 2005). Hepcidin is thought to release a small antimicrobial peptide which inhibits iron absorption, as well as aid in defense against bacterial infection (Syed et al., 2006). Thus, the hormone hepcidin aids with regulating iron in the body by decreasing in individuals with iron deficiency, to allow an increase in transferrin receptors on cell surfaces.

Since heme and nonheme iron are absorbed differently, bioavailability is different. Studies have demonstrated that the bioavailability of iron from foods is utilized at 0 to 15\% (Krajcovicova-Kudlackova et al., 2003). Researchers found heme iron to be about $23 \%$ absorbable compared to nonheme iron which has an absorption rate between 3 to 
$8 \%$, when adjusting for dietary enhancing or inhibiting factors (Tseng et al., 1997).

Researchers stated that nonheme iron absorption is lower for those consuming vegetarian diets than for those eating a nonvegetarian diet (IOM, 2004). Nonheme iron absorption was significantly less from the lacto-ovo-vegetarian diet at $1.1 \%$ than from the nonvegetarian diet at $3.8 \%$. Nonheme iron absorption from the lacto-ovo-vegetarian diet was $70 \%$ lower than the nonvegetarian diet (Hunt \& Roughead, 1999). Thus, it is important for vegetarians to consume a large amount of nonheme iron with iron absorption enhancers to meet the body's iron requirement.

\section{Factors Affecting Iron Absorption}

There are many dietary factors that can influence the amount of heme and nonheme iron absorbed in the body. It has been estimated that $40 \%$ of iron consumed would be absorbed if there were no enhancing or inhibiting factors present (Hallberg \& Hulthen, 2000). Total variation in iron absorption in one study was found to be $85 \%$, with $31 \%$ due to dietary factors and the remaining percentage from subject variability. In this study the strongest dietary factors influencing iron absorption were phosphorus, ascorbic acid, and animal tissue (Cook \& Reddy, 2001). There are many other enhancers and inhibitors of iron absorption.

Enhancers of Iron Absorption. Dietary factors known to influence iron absorption by enhancing the amount of iron absorbed include vitamin $\mathrm{C}$, the meat poultry fish factor (MPF), as well as other factors. Vitamin $\mathrm{C}$ or ascorbic acid is known to enhance iron absorption when co-ingested with iron because of its ability to reduce ferric iron to ferrous iron. It can also bind ferrous iron, so both can be absorbed together at the brush border (Mahan \& Escott-Stump, 2004). One study examining green leafy vegetables, 
which are high in iron, found a significant positive correlation between ascorbic acid and iron dialysability. Therefore, as one increases vitamin $\mathrm{C}$ intake when consuming iron rich foods, iron absorption is increased. In this study iron dialysability was increased by $53 \%$ with the addition of ascorbic acid. For example, lemon juice added to uncooked green leafy vegetables may increase iron absorption (Chiplonkar, Tarwadi, Kavedia, Mengale, Paknikar, \& Agte, 1999). In children, iron absorption increased from $5.1 \%$ to $8.2 \%$ after the ratio of ascorbic acid to iron was increased (Davidsson, Walczyk, Zavaleta, \& Hurrell, 2001). This was also found when researchers doubled the ratio of iron and ascorbic acid in infant formulas (Davidsson, Dimitriou, Walczyk, \& Hurrell, 2001). Thus, it is evident that the addition of a vitamin $\mathrm{C}$ rich food to iron rich foods will aid in the absorption of iron. When examining hematological measures, a significant positive correlation was found between vitamin $\mathrm{C}$ intake and serum ferritin concentrations (Wilson \& Ball, 1999) as well as hemoglobin (Chiplonkar et al., 2003). This was also found when lacto-ovo-vegetarians consumed tofu and $303 \mathrm{mg}$ per day of orange juice (Kandiah, 2002), and when both iron and vitamin $\mathrm{C}$ in the form of fruit juice were consumed (Thane et al., 2003). Thus, vitamin C positively influences measures of iron status. In contrast, Cook and Reddy (2001) found no significant difference in the mean iron absorption despite the range of dietary vitamin $\mathrm{C}$ intake, when studying complete diets from three different dietary periods rather than from single meals (Cook \& Reddy, 2001). Another study found that even though vegetarians consumed a significantly higher amount of vitamin C, they had low serum ferritin levels (Harman \& Parnell, 1998). These results may have been influenced by other factors influencing iron absorption. 
Animal proteins such as beef, pork, veal, lamb, liver, fish, and chicken enhance the absorption of iron through a substance called the 'meat factor' or 'meat, poultry, and fish factor' (MPF). Although the cause is unknown, it is believed that specific amino acid or dipeptide digestion produced may enhance iron absorption (Mahan \& Escott-Stump, 2004). The MPF factor only affects meat eaters and is influenced by the type and amount of meat consumed (Donovan \& Gibson, 1995). A study evaluating nonheme iron absorption in lean pork found 25 grams of meat did not significantly increased iron absorption, where as 50 grams of meat significantly increased absorption by $44 \%$, and 75 grams of meat significantly increase absorption by 57\% (Baech et al., 2003). Therefore, the greater amount of meat consumed the greater amount of nonheme or plant based iron is absorbed. It was also found that iron absorption increased significantly as the amount of beef in the diet increased. However, the study showed that there is little additional benefit in the inclusion of more than three ounces of lean beef per day. These results reinforce that beef increases the bioavailability or iron (Johnson \& Walker, 1992). A few studies with small sample sizes have shown no significant differences with respect to iron absorption when including meat in the diet. A randomized, cross-over design study with 19 female subjects examined nonheme iron absorption in individuals consuming Danish pork, Polish pork, and in vegetarians, yet found no difference among treatment groups (Kristensen, Hels, Morberg, Marving, Bugel, \& Tetens, 2005). Another study comparing 14 women consuming various amounts of meat found no significant difference in iron balance. However, high meat intake of 289 grams was associated with lower iron status (Hunt, Gallagher, Johnson, \& Lykken, 1995). This indicates that there may be a 
maximum threshold effect of animal protein consumed that will positively influence iron absorption.

Additional factors thought to enhance the absorption of iron include human milk due to the presence of lactoferrin, alcohol because it enhances gastric acid secretion, and soy sauce (Hallberg \& Hulthen, 2000). Syed et al. (2006) also suggests egg whites due to the presence of ovotransferrin and sugar as enhancers of iron absorption. Lastly, sulfurcontaining amino acids are thought to enhance iron absorption because they form chelates with ionic iron (Mahan \& Escott-Stump, 2004).

Inhibitors of Iron Absorption. The dietary factors known to inhibit iron absorption include calcium, phytates, tannins, as well as other dietary factors. It was estimated that iron absorption was reduced by $25 \%$ in meals with higher calcium content (Hallberg \& Hulthen, 2000). In European infants, the strongest negative determinate of iron status was an early introduction of cow's milk (Male et al., 2001). This may be due to the lower iron content of cow's milk compared to human breast milk or infant formula. The effect of calcium on nonheme iron absorption found that as calcium intake increased from $280 \mathrm{mg}, 684 \mathrm{mg}$, to $1281 \mathrm{mg}$ per day, iron absorption decreased from $5.83 \%$, $5.01 \%, 4.71 \%$, respectively. These results were not significant, therefore researchers concluded that inhibiting one factor may not exert a strong enough influence on overall iron absorption (Reddy \& Cook, 1997). In contrast, researchers did not find a positive or negative effect on iron absorption when adding milk or yogurt to Mexican women's diets. According to the researchers this outcome may have been due to the already rich calcium and phytate content of the Mexican diet (Rosado, Diaz, Gonzalez, Griffin, Abrams, \& Preciado, 2005). 
Organic phosphate, found in cereals, bran, legumes, and nuts, have also been associated with a strong deleterious affect on iron absorption (Herbert, 1992). It has been estimated that phosphate can inhibit $12 \%$ to $100 \%$ of iron absorption in the body (Johnson \& Walker, 1992; Mahan \& Escott-Stump, 2004; Pongstaporn \& Bunyaratavej, 1999; Tseng et al., 1997). Increased pytic acid may reduce nonheme iron absorption by reducing iron solubility in the intestinal lumen and entry into the intestinal mucosa (Hunt \& Roughead, 1999). Soy has a high content of phytate and has been found to have an average iron absorption ratio of 0.33 after correction for its high calcium content (Hallberg \& Hulthen, 2000). Vegetarians and nonvegetarians in Slovakia were found to have a prevalence of iron deficiency because of higher intakes of plant trace elements high in phytate (Krajcovicova-Kudlackova et al., 2003). In healthy women, findings showed a significant mean iron absorption increase from $20.7 \%$ to $33.1 \%$ after enzymatic degradation of phytic acid (Davidsson, Dimitriou et al., 2001). Phytate intake has also been shown to be negatively associated $(\mathrm{p}=0.05)$ with serum ferritin, the storage form of iron (Patterson, Brown, Roberts, 2001). As for the beneficial affects of phytate, there is an influencing effect on ascorbic acid when phytates are present in the diet (Hallberg \& Hulthen, 2000). It is estimated that around $120 \mathrm{mg}$ of ascorbic acid is required to overcome the phytate effect on the basic meal (Baech et al., 2003).

Tannis or polyphenols from tea, coffee, red wine, and cocoa are also known to reduce nonheme irons absorption by 50\% (Cooper, Cockell, \& L'Abbe, 2006; Herbert, 1992; Mahan \& Escott-Stump, 2004; Pongstaporn \& Bunyaratavej, 1999). One study found polyphenals from tea $(200 \mathrm{~mL})$ can reduce iron absorption by $75 \%$ to $80 \%$ and a cup of coffee $(150 \mathrm{~mL})$ can reduce iron absorption by $60 \%$ (Hallberg \& Hulthen, 2000). Other 
studies used an adjustment for iron absorption of $60 \%$ to $100 \%$ for tea consumed with a meal (Tseng et al., 1997). In British children who drank coffee, results showed they had poor iron status as evidenced by low hemoglobin levels (Thane et al., 2003). Thus, it may be beneficial for individuals with iron deficiency to avoid tee, coffee, cocoa, and red wine with meals high in iron.

Other known inhibitors of iron absorption include fiber (Harman \& Parnell, 1998; Pongstaporn \& Bunyaratavej, 1999), flavonoids, as well as eggs which can reduce iron absorption by $27 \%$ (Hallberg \& Hulthen, 2000; Mahan \& Escott-Stump, 2004). Another researcher also mentioned antacids and oxalates as inhibitors of iron absorption. Thus, even though spinach is high in iron, it also contains oxalate, causing approximately $1.5 \%$ of the iron to be absorbed (Cooper et al., 2006; Herbert, 1992).

\section{Iron Excretion}

About $85 \%$ of red blood cells have a mean functional lifetime of 120 days. Hemoglobin degradation is re-released in the body bound to transferrin or ferritin, in which $0.66 \%$ is recycled each day (Beard, 2001). Iron can be lost from the body through bleeding, defecation, sweat, and exfoliation of hair and skin. However, iron is primarily excreted through bile (Mahan \& Escott-Stump, 2004). Fecal iron represents iron that was never absorbed in the body and has not been shown to account for substantial iron excretion (Hunt \& Roughead, 1999). Researchers have stated, that to find homeostasis with iron in the body the amount of iron absorbed must approximate iron losses (Hallberg \& Hulthen, 2000). 


\section{Recommended Dietary Allowance of Iron}

The Dietary Reference Intakes (DRI) are a set of nutrient based reference values that have been expanded and replaced the former Recommended Dietary Allowance (RDA) in the United States and the Recommended Nutrient Intakes (RNI) in Canada (Cooper, 2006; U. S. DHHS, 2005). The RDA's were set to meet the needs of $97 \%$ to $98 \%$ of all healthy individuals and take into account the varying degrees of iron absorption. The DRI's act as reference values and include the RDA's, the Estimated Average Requirements (EAR), Adequate Intakes (AI), and Tolerable Upper Intake Levels (UL) (U. S. DHHS, 2005). The RDA of iron for females aged 14 to 18 years is $15 \mathrm{mg}$ per day, with an EAR of 7.9 mg per day (IOM, 2004; Mahan \& Escott-Stump, 2004). For females aged 19 to 30 years the RDA is $18 \mathrm{mg}$ per day, with an EAR of $8.1 \mathrm{mg}$ per day for females (IOM, 2004; Mahan \& Escott-Stump, 2004). Other studies mention that daily iron intake of iron in individuals on a typical western diet ranges from 12 to $18 \mathrm{mg}$ per day (Syed et al., 2006). The UL of iron intake for females is $45 \mathrm{mg}$ per day (IOM, 2004; Mahan \& Escott-Stump, 2004). Table 4 gives the RDA in bold or the AI if the RDA is not available, the UL, and the EAR values for iron in individuals.

The recommendations in Table 4 have assumed that $75 \%$ of the iron was from heme iron sources (Mahan \& Escott-Stump, 2004). It has been suggested that the iron requirement for those consuming a vegetarian diet is approximately 1.8-2.0 fold greater than for those consuming a nonvegetarian diet (Cooper et al., 2006; IOM, 2004). A few studies have actually calculated the Recommended Dietary Allowance for bioavailabile iron density. Researchers used a calculation of $0.75 \mathrm{mg}$ of iron per 1000 calories based on a basal iron requirement of $1.5 \mathrm{mg}$ per day and energy requirements of 2000 calories 
Table 4. The Dietary Reference Intake of Iron

\begin{tabular}{|c|c|c|c|}
\hline & $\begin{array}{c}\text { Recommended Dietary } \\
\text { Allowances or } \\
\text { Adequate Intakes }\end{array}$ & $\begin{array}{c}\text { Tolerable } \\
\text { Upper Intake }\end{array}$ & $\begin{array}{c}\text { Estimated } \\
\text { Average } \\
\text { Requirement }\end{array}$ \\
\hline Age/Life Stage & Iron (mg/day) & Iron (mg/day) & Iron (mg/day) \\
\hline \multicolumn{4}{|l|}{ Infants } \\
\hline 0-6 months & 0.27 & 40 & \\
\hline 7-12 months & 11 & 40 & 6.9 \\
\hline \multicolumn{4}{|l|}{ Children } \\
\hline $1-3$ years & 7 & 40 & 3.0 \\
\hline 4-8 years & 10 & 40 & 4.1 \\
\hline \multicolumn{4}{|l|}{ Males } \\
\hline 9-13 years & 8 & 45 & 5.9 \\
\hline 14-18 years & 11 & 40 & 7.7 \\
\hline 19-30 years & 8 & 40 & 6.0 \\
\hline $31-50$ years & 8 & 40 & 6.0 \\
\hline $51-70$ years & 8 & 40 & 6.0 \\
\hline$>70$ years & 8 & 40 & 6.0 \\
\hline \multicolumn{4}{|l|}{ Females } \\
\hline 9-13 years & 8 & 40 & 5.7 \\
\hline 14-18 years & 15 & 45 & 7.9 \\
\hline 19-30 years & 18 & 45 & 8.1 \\
\hline $31-50$ years & 18 & 45 & 8.1 \\
\hline $51-70$ years & 8 & 45 & 5.0 \\
\hline$>70$ years & 8 & 45 & 5.0 \\
\hline \multicolumn{4}{|l|}{ Pregnant } \\
\hline$<18$ years & 27 & 45 & 23.0 \\
\hline 19-30 years & 27 & 45 & 22.0 \\
\hline $31-50$ years & 27 & 45 & 22.0 \\
\hline \multicolumn{4}{|l|}{ Lactating } \\
\hline$<18$ years & 10 & 45 & 7.0 \\
\hline 19-30 years & 9 & 45 & 6.5 \\
\hline $31-50$ years & 9 & 45 & 6.5 \\
\hline
\end{tabular}

Note. Recommended Dietary Allowance (RDA) values are in Bold. If the RDA is not available the Adequate Intake (AI) is given.

Modified from IOM, 2004; Mahan \& Escott-Stump, 2004

per day (Chiplonkar et al., 1999). Another study estimated that adolescent females

between 14 and 19 years old have a daily requirement of 1.4 to $1.7 \mathrm{mg}$ per day of iron.

This figure was calculated from a mean basal loss of 0.72 to $0.85 \mathrm{mg}$ of iron per day, a requirement of growth and stores of 0.10 to $0.41 \mathrm{mg}$, and a median menstrual loss of 0.5 
to $0.6 \mathrm{mg}$ per day (Donovan \& Gibson, 1995). The number of people meeting the Recommended Dietary Allowance of iron is unclear. One study reported $66 \%$ of the lacto-ovo-vegetarians, $10 \%$ of the semi-vegetarians, and $24 \%$ of the nonvegetarians studied had iron intake below their Estimated Average Requirement (Donovan \& Gibson, 1995).

\section{Iron Deficiency}

The Dietary Guidelines for America 2005 states "The actual prevalence of inadequacy for a nutrient can be determined only if an Estimated Average Requirement (EAR) has been established and the distribution of usual dietary intake can be obtained (U. S. DHHS, 2005). As shown in Table 4, iron's Estimated Average Requirement for females is much lower than the Recommended Dietary Allowance.

Anemia in general has been defined as a decreased concentration of hemoglobin or red blood cell mass in the blood (Shine, 1997). A complete blood count (CBC) provides electronically measured mean corpuscular volume (MCV) and mean cell hemoglobin concentration (MCHC), which are indicators of anemia. MCV measures the size of the red blood cell and is derived from hematocrit and red blood cell count (Shine, 1997). The

normal range of MCV is 78 to 98 femtoleters (fl) in adults (Shine, 1997). Iron deficiency anemia is classified as microcytic, with MCV less then $78 \mathrm{fl}$ (Shine, 1997). MCHC looks at the shade of red in the cells and is derived from hemoglobin and hematocrit. Normal levels of MCHC range from 32 to $36 \mathrm{~g} / \mathrm{dL}$. Low levels of MCHC are called hypochromic for pale color, which are seen in individuals with iron deficiency anemia (Mahan \& Escott-Stump, 2004). 
Iron deficiency anemia is characterized by the production of small (microcytic) and pale (hypochromic) erythrocytes (Herbert, 1992). Nutritional causes of iron deficiency may be inadequate iron intake, consumption of poorly available forms of iron, or decreased iron absorption due to dietary inhibitors (Cooper et al., 2006). It may also result from increased demands on iron for growth, menstrual blood loss, or pregnancy (Cooper et al., 2006). Some drugs can cause interference with iron absorption including antacids, cholestyramine, cimetidine (Tagamet), pancreantin, ranitidine (Zantac), and tetracycline, as well as secondary effects of chronic disease (Mahan \& Escott-Stump, 2004). In European infants studied, the prevalence of anemia was $9.4 \%$, with $40 \%$ of the anemia's associated with increased infections. Iron deficiently was classified in $7.2 \%$ infants, with iron deficiency anemia classified in $2.3 \%$ infants (Male et al., 2001). The classifications of negative iron balance will be discussed later in the Review of Literature.

\section{Hematological Values Related to Iron Status}

Findings of microcytic, hypochromic, and low hemoglobin can diagnose inadequate hemoglobin synthesis, but does not indicate iron deficiency from lead poisoning or a globin defect such as thalassemia (Herbert, 1992). Therefore, iron status can also be assessed via serum iron, total iron binding capacity, transferrin saturation, transferrin receptor, and serum ferritin (Mahan \& Escott-Stump, 2004). Some researchers in India used serum iron as an indicator of iron deficiency and found lacto-ovo-vegetarians to have significant lower median serum iron compared to nonvegetarians (Chiplonkar et al., 2003). However, due to the large day-to-day fluctuations and its insensitivity to early iron depletion, serum iron is a poor index of iron status (Herbert, 1992; Mahan \& EscottStump, 2004). 
Total iron binding capacity determines the concentration of transferrin or the potential for a plasma protein to bind a ferric iron ion $(\mathrm{Fe}+3)$. The transferrin molecule binds two ferric ions $(\mathrm{Fe}+3)$ and two bicarbonate ions at separate sites, and delivers iron to cells for hemoglobin production and other uses (Herbert, 1992; Mahan \& Escott-Stump, 2004). Transferrin has a half life of eight days and is a negative acute phase respondent, thus decreases during inflammatory conditions (Herbert, 1992). Total iron binding capacity depends on the number of free binding sites on the transferrin molecule and is regulated by intracellular iron availability (Mahan \& Escott-Stump, 2004). Therefore, transferrin concentration or saturation increases in those with iron deficiency giving more free binding sites. In individuals with iron deficiency, transferrin saturation is increased so the total iron binding capacity increases, making it an early indicator of increased iron absorption (Herbert, 1992). However, total iron binding capacity is also known to increase in individuals with chronic diseases (Herbert, 1992). Therefore, some individuals believe total iron binding capacity and transferrin saturation can not specifically detect iron stores or iron deficiencies (Mahan \& Escott-Stump, 2004).

Serum transferrin receptors are another index of iron status, which mediate iron uptake into cells (Beard, 2001). Transferrin receptors are generated on the surface of the red blood cell and increase in response to the need for iron. Iron decreases in the cellular pool with iron deficiency, causing an up-regulation of iron intake into cells and a down regulation of synthesis of iron storage protein (Beard, 2001). The day to day variations of serum transferrin receptors are lower than that of ferritin (the storage form of iron), making it a good indicator of iron status (Mahan \& Escott-Stump, 2004). 
Ferritin is a storage protein that sequesters iron normally gathered in the liver, spleen, and bone marrow. Serum ferritin concentrations are directly proportional to the amount of ferritin inside storage cells and are an excellent indicator of the size of the body's iron storage pool (Herbert, 1992; Mahan \& Escott-Stump, 2004). Therefore, a decrease in serum ferritin is an early indicator of negative iron balance. Studies have proposed that the optimal approach to assessing the iron status of a population is to use serum ferritin, because it is most sensitive index for iron deficiency before anemia is present (Cooper \& Zlotkin, 1996; Herbert, 1992; Pongstaporn \& Bunyaratavej, 1999; Shine, 1997). Fecal ferritin is directly associated with serum ferritin and is substantially less in lacto-ovovegetarian diets compared to the nonvegetarian diets. Researchers suggest it is due to the adaptation to increase the efficiency of iron absorption in the lacto-ovo-vegetarian diet (Hunt \& Roughead, 1999). Serum ferritin is an acute phase reactant, which rises during inflammatory states (Herbert, 1992; Mahan \& Escott-Stump, 2004). However, when serum ferritin is elevated it is still recommended as a marker for a disorder needing further evaluation (Herbert, 1992).

Hemoglobin concentrations are a diagnostic tool for iron deficiency anemia because it is affected late in the disease. However, low hemoglobin does not reveal the type of anemia. Low hemoglobin levels reflecting iron deficiency anemia were found in $0 \%$ to $5 \%$ of the Dutch adult population studied. Researchers indicate that only $16 \%$ of men's and $13 \%$ of women's hemoglobin levels could be explained by physiological and dietary factors (Brussaard et al., 1997). One study showed similar concentrations of hemoglobin among vegetarians and nonvegetarians (Harman \& Parnell, 1998). Thus, hemoglobin should not be the only hematological indicator for iron status. 
Two other hematological values that show significance in relation to iron status are red blood cell width (RBW) and lymphocytes. It was found that red blood cell width and lymphocytes were significantly higher in vegetarians compared with nonvegetarians (Pongstaporn \& Bunyaratavej, 1999).

\section{Stages of Iron Deficiency}

About 6\% of Americans are in significant negative iron balance (Herbert, 1992). Thus, it is important to routinely measure and assess individual's stage of iron balance. Negative iron balance ranges from stage I to stage IV. Stage I and II of negative iron balance or iron depletion represents over half of all cases of negative iron balance (Herbert, 1992). In these stages iron stored in the liver and bone marrow are depleted, but there is no dysfunction (Cooper et al., 2006). Stage I is reduced iron absorption, producing moderately depleted iron stores. Stage II has severely depleted iron stores without dysfunction, which is best recognized by measuring serum ferritin (Herbert, 1992). Stage III and IV of negative iron balance represents iron deficiency characterized by inadequate body iron causing dysfunction and disease. Stage III dysfunction is not accompanied by anemia, where as in stage IV iron deficiency anemia does occur (Cooper et al., 2006; Herbert, 1992; Mahan \& Escott-Stump, 2004). Stage IV is characterized by the appearance of microcytic and hypochromic erythrocytes (Fairweather-Tait, 2004). Table 5 shows selected hematological values at different stages of iron balance (Fairweather-Tait, 2004; Herbert, 1992; Mahan \& Escott-Stump, 2004; U. S. NLM \& NIH, 2007). 
Table 5. Stages of Iron Balance

\begin{tabular}{|l|l|l|l|l|}
\hline \multicolumn{2}{|l|}{ Depletion } & Deficiency \\
\hline & Stage I & Stage II & Stage III & Stage IV \\
\hline & $\begin{array}{l}\text { Early } \\
\text { negative } \\
\text { iron balance }\end{array}$ & $\begin{array}{l}\text { Iron } \\
\text { Depletion }\end{array}$ & $\begin{array}{l}\text { Damaged } \\
\text { metabolism; } \\
\text { iron-deficient } \\
\text { erythropoiesis }\end{array}$ & $\begin{array}{l}\text { Clinical } \\
\text { damage; iron } \\
\text { deficiency } \\
\text { anemia }\end{array}$ \\
\hline $\begin{array}{l}\text { Hemoglobin } \\
(\text { women })(\mathrm{g} / \mathrm{L})\end{array}$ & - & $>120$ & $>120$ & $<120$ \\
\hline $\begin{array}{l}\text { Serum Iron } \\
(\mu \mathrm{g} / 100 \mathrm{ml}=\mu \mathrm{g} / \mathrm{dL})\end{array}$ & $<120$ & $<115$ & $<60$ & $<40$ \\
\hline $\begin{array}{l}\text { TIBC* } \\
(\mu \mathrm{g} / 100 \mathrm{ml}=\mu \mathrm{g} / \mathrm{dL})\end{array}$ & $300-360$ & $>360$ & $>390$ & $>410$ \\
\hline $\begin{array}{l}\text { Transferrin Saturation } \\
(\%)\end{array}$ & $<30$ & $<30$ & $<15$ & $<15$ \\
\hline $\begin{array}{l}\text { Serum Ferritin } \\
(\mu \mathrm{g} / \mathrm{L}=\mathrm{ng} / \mathrm{mL})\end{array}$ & $<25$ & $<20$ & $<10$ & $<10$ \\
\hline \begin{tabular}{l} 
Erythrocytes \\
\hline
\end{tabular} & Normal & Normal & Normal & $\begin{array}{l}\text { Microcytic/ } \\
\text { hypochromic }\end{array}$ \\
\hline
\end{tabular}

- Not available. * Total iron binding capacity.

Modified from Fairweather-Tait, 2004; Herbert, 1992; Mahan \& Escott-Stump, 2004; U. S. NLM \& NIH, 2007

Not all researchers use the same criteria for defining iron status. An Australian study looking at women of childbearing age defined iron deficiency as "either serum ferritin less than $15 \mathrm{mug} / \mathrm{L}$; or serum ferritin 15-20 mug/L, with two other haematological parameters indicative of iron deficiency" (Patterson et al., 2001). Iron replete individuals had hemoglobin greater than $120 \mathrm{~g} / \mathrm{L}$ and serum ferritin greater than 20 mug/L (Patterson et al., 2001). Another study looking at European infants defined anemia as hemoglobin less than $110 \mathrm{~g} / \mathrm{L}, \mathrm{MCV}$ less than $70 \mathrm{fl}$, serum ferritin less than $10 \mu \mathrm{g} / \mathrm{L}$, and transferrin saturation less than $10 \%$ (Male et al., 2001). Iron deficiency was defined as the presence of two or more abnormal values of MCV, serum ferritin, transferrin saturation and transferrin receptors. Iron deficiency anemia was defined as anemia plus two or more 
abnormal iron status indicators (Male et al., 2001). Thus, study results must be carefully examined to determine iron deficiency or iron deficiency anemia in a population. Individuals Most Affected

In the United States iron deficiency anemia is most prevalent among children and women of child bearing age (Mahan \& Escott-Stump, 2004). This is also apparent in India where iron deficiency was present in $40.8 \%$ of women compared to $27.9 \%$ of men (Chiplonkar et al., 2003). Other characteristics of individuals with poor iron status include those who were non-Caucasian and vegetarian in Britain (Thane et al., 2003). Iron deficiency anemia may be more frequent with low socio-economic status at $5.1 \%$ compared to high socio-economic status at 0\% (Male et al., 2001). However, it was found that parity, marital status, employment, and education appear to play no role in iron deficiency (Patterson et al., 2001).

\section{Symptoms of Iron Deficiency}

With iron deficiency the overt symptoms of anemia are manifested. These include feeling tired, run down, lassitude, fatigued, having headaches, lack of energy, and irritability (Beard, 2001; Herbert, 1992). Clinical signs include a smooth, waxy, and glistening appearance on the tongue called glossitits, angular stomatitis which is a form of dysphagia, spoon shaped nails called koilonychias, and lab values indicating microcytic and hypochromic anemia (Beard, 2001). Other symptoms include pale skin, pink lower eyelids, gastritis with low stomach acid levels (Mahan \& Escott-Stump, 2004), dyspnea, tachycardia, angina, congestive failure, edema, and decrease cold tolerance (Herbert, 1992). Behavioral changes such as pica and pagophagia (ice eating) can occur (Beard, 2001). Mental functions can also be affected during iron deficiency. 
The brain obtains iron from transferrin receptors on cells in the brain, with an increase in iron uptake when iron status is low. In children brain development may be affected due to iron fluctuations and accumulations (Beard, 2001). Restless leg syndrome and involuntary muscle contractions may also be caused by perturbed movement of iron in the brain (Beard, 2001). Physiological manifestations have been noted in immune function, thermoregulatory performance, energy metabolism, and exercise or work performance (Beard, 2001). As for immune function, iron is required by the body for mounting an effective immune response, because it is a critical component of proper enzymatic function of immune cells (Beard, 1992). Therefore, there is an increased risk of infection in individuals with iron deficiency. When untreated it has been noted that anemia can result in cardiovascular and respiratory changes which can lead to cardiac failure (Mahan \& Escott-Stump, 2004).

\section{Treatment for Iron Deficiency}

Treatment for iron deficiency varies according to the level of iron depletion. A panel of physicians was asked to determine the appropriateness for evaluating patients and medical treatment for anemia. Researchers found that physicians rated it appropriate to do basic evaluations such as blood tests if women between the 18 to 49 years had a hemoglobin level of $\leq 12 \mathrm{~g} / \mathrm{dL}$ (Dubois, Goodnough, Ershler, Winkle, \& Nissenson, 2006). For hemoglobin levels $9.5-10.9 \mathrm{~g} / \mathrm{dL}$ physicians thought it was appropriate to use prescribe erythropoietic growth factors, hemoglobin of $<9.5 \mathrm{~g} / \mathrm{dL}$ it was appropriate to use erythropoietic growth factors or a transfusion if over the age of 70 , and if the hemoglobin was $<8 \mathrm{~g} / \mathrm{dL}$ the use of either transfusion or erythropoietic growth factor was deemed appropriate (Dubois et al., 2006). However, this study only used hemoglobin as 
an indicator of anemia. As discussed, other hematological measurements can be used to determine iron deficiency anemia.

Changes in an individuals' diet can also be an effective treatment for iron deficiency, as discussed in previously in the Review of Literature. Poor iron status may be reduced by the consumption of heme and nonheme iron rich foods, iron fortified foods, or enhancers of nonheme iron (Thane et al., 2003). Foe example, studies suggest eating raw green leafy vegetables because they are a good source of ascorbic acid (Tarwadi \& Agte, 2003), which increases the bioavailability of nonheme iron (Chiplonkar et al., 1999).

Another way to treat iron deficiency is through the use of pharmacological iron supplementation. However, researchers found iron supplements to be only slightly effective. This may be due to lack of compliance, because of side effects including diarrhea, constipation, epigastria, nausea, and meteorism. Therefore, the ferrous form of oral iron supplements has been recommended because it is less toxic and has equal or higher bioavailability (Boccio \& Iyengar, 2003). Iron supplements are usually taken between meals to prevent inhibitory influences on iron absorption from foods. The daily dose of iron can range from 100 to $200 \mathrm{mg}$ and is usually divided into three times per day (Boccio \& Iyengar, 2003). One study demonstrated that supplementation did help increase serum ferritin and hemoglobin, when participants consumed $37.5 \mathrm{mg}$ of iron three times a day for six weeks (Samuelson, Bratteby, Berggren, Elverby, \& Kempe, 1996).

\section{Factors Influencing Iron Status}

Iron status may also be altered via exercise, blood donation, smoking, oral contraceptives, menstruation, and the use of supplements. During exercise and stressful 
conditions of training, there is an increase loss of iron through the gut (Mahan \& EscottStump, 2004). This may be due to an increase in movement of nutrients through the gut. As for blood donation, low blood volume can deplete iron in the blood. One study found a negative association with serum ferritin when participants had donated blood six months prior to the study (Brussaard et al., 1997). Smoking may also impact poor iron status. Thane et al. (2003) stated "girls aged 15-18 years who smoked were more likely to report low dietary than non-smokers." Most studies found nonvegetarians to be more likely to smoke daily compared to vegetarians (Cade et al., 2004; Greenwood et al., 2000; Key et al., 1998). In Slovakia, none of the vegetarians smoked compared to $25 \%$ of the nonvegetarians (Krajcovicova-Kudlackova et al., 2003). However, in France, $6 \%$ of vegetarians smoked (Leblanc et al., 2000). In contrast, one study found no significant difference (Patterson et al., 2001) and another study found more vegetarians smoked compared to nonvegetarians (Ball \& Bartlett, 1999). It is unclear as to which dietary group smokes more often but iron status may be altered negatively in those who do smoke.

Different medications have also been examined to determine influence on iron status. A study examining aspirin use in elderly found those taking more than seven aspirin per week had a significantly lower mean serum ferritin compared to those taking less than one aspirin per week. Researchers believe this is possibly due to increased blood loss, which is dose dependent, or the fact that ferritin is an acute phase protein whose blood concentration is influenced by pro-inflammatory cytokines (Fleming, Jacques, Massaro, D’Agostino, Wilson, \& Wood, 2001). The use of oral contraceptives has also been shown to influence iron status in women. It was found that iron deficient women 
experienced increased menstrual blood loss compared to iron replete women (Patterson et al., 2001). Oral contraceptive use tends to reduce menstrual blood loss leading to better iron status. However, researchers have found iron absorption to be less efficient in those who used oral contraceptives (Hunt \& Roughead, 1999). Studies have shown that oral contraceptive use has been positively associated with serum ferritin (Hunt \& Roughead, 1999; Patterson et al., 2001). Of nearly 52,000 women studied in the United Kingdom almost three quarters took oral contraceptive at one time (Davey et al., 2003). Some studies examining iron status have required participants not to use oral contraceptives, however other studies fail to eliminate vegetarians and nonvegetarians using oral contraceptives (Davidsson, Dimitriou et al., 2001; Kandiah, 2002). Individuals taking oral contraceptives may cause potentially skewed iron status results.

Menstrual blood loss greatly influences iron status. Women lose an average of 0.5 mg per day of iron through menstruation, with approximately $5 \%$ of women losing more than 1.4 mg per day (Mahan \& Escott-Stump, 2004). Menstrual blood iron loss has been found to be negatively associated with iron stores and found to contribute $11.5 \%$ of the deviance of iron status in women studied. Women with high menstrual blood loss have a greater possibility of iron deficiency, which may be alleviated with the use of oral contraceptives (Harvey et al., 2005). In vegetarian women with heavy menstrual blood loss, median serum ferritin was lower than those with light losses (Alexander et al., 1994). In contrast some studies refute any differences in serum ferritin between menstruating and nonmenstruating women (Samuelson et al., 1996). More over, researchers found no difference in menstrual blood loss between women consuming nonvegetarian diets and vegetarian diets. However, these results may be skewed because 
$35.5 \%$ of the participants used oral contraceptives (Harvey et al., 2005). Some researchers suggest menstrual blood loss has more of an influencing factor than dietary intake (Harman \& Parnell, 1998). It was noted that the average women consumes $12 \mathrm{mg}$ of iron or $67 \%$ of the RDA, which meets the needs of few menstruating women (Mahan \& Escott-Stump, 2004).

Vitamin and mineral supplements can influence iron status. Nonvegetarians had the lowest prevalence of multivitamin and multi-mineral supplement use (Ledikwe et al., 2006) compared to vegetarians and vegans (Alexander et al., 1994; Cade et al., 2004; Larsson \& Johansson, 2002). One study reported that $30 \%$ of the vegetarians studied took nutritional supplements compared to $20 \%$ of the nonvegetarians, yet none of the supplements were iron containing (Shaw et al., 1995). Female vegetarians had a higher median supplemental intake of calcium, iron, magnesium, potassium, niacin, folic acid, vitamins A, vitamin D, and vitamin B12 compared to the nonvegetarians (Bedford \& Barr, 2005). In fact, one study revealed $14 \%$ of vegetarians took iron supplements more than three times a week compared to none among nonvegetarians (Ball \& Bartlett, 1999). Others findings reported that 2 out of 21 women taking $18 \mathrm{mg}$ of iron supplements per day, tended to have higher serum ferritin concentrations and lower iron absorption (Hunt \& Roughead, 1999). This may be due to the lack of heme iron, negligible amounts of nonheme iron and calcium, and sizable amounts of vitamin $\mathrm{C}$ in dietary supplements (Thane \& Bates, 2000). The adoption of some degree of dietary restriction in the form of vegetarianism might be expected to increase the likelihood of using dietary supplements because of concerns about dietary adequacy (Kirk, Cade, Barrett, \& Conner, 1999). 


\section{Vegetarians and Iron Status}

Iron intake in vegetarians and nonvegetarians differ among research studies. Many studies reveal that vegetarians and vegans have the highest intake of iron compared to nonvegetarians (Cade et al., 2004; Davey et al., 2003; Perry et al., 2002). It is important for vegetarians to consume higher amounts of nonheme iron because the bioavailability of iron in the vegetarian diet is expected to be lower due to the absence of heme iron (Davey et al., 2003; Perry et al., 2002). European vegans consumed more iron at $14.1 \mathrm{mg}$ of iron per day compared to vegetarians and nonvegetarians at $12.6 \mathrm{mg}$ per day. These levels are below the Recommended Nutrient Intake for pre-menopausal women and could lead to an increase risk for iron deficiency (Davey et al., 2003). Among vegetarian groups studied in France, vegans and lacto-ovo-vegetarians consumed more iron than lacto-vegetarians. However, over time vegans became more restrictive and where more likely to be deficient in iron (Leblanc et al., 2000). A study in the United Kingdom found lacto-ovo-vegetarians to have higher intakes of iron compared to nonvegetarians. However, $35.5 \%$ of the subjects used oral contraceptives, resulting in higher concentrations of transferrin receptors in the lacto-ovo-vegetarians (Harvey et al., 2005). Thus, the use of oral contraceptives may have decreased the absorption of iron causing hematological values to indicate lower iron status.

In contrast, other findings reveal that vegetarians have lower iron intake compared to non-vegetarians (Krajcovicova-Kudlackova et al., 2003; Mahan \& Escott-Stump, 2004). Vegetarian Seventh-Day Advensists in Brazil had lower ingestion of iron at $7.62 \mathrm{mg}$ per day compared to nonvegetarians at $10.53 \mathrm{mg}$ per day. Researchers believe these results may have been due to the absence of heme iron in the vegetarian diet and that Seventh- 
Day Adventists do not consume fruit after their meals. Therefore, the enhancing affect of vitamin $\mathrm{C}$ on iron absorption is not present (Meirelles et al., 2001). Other studies report that $42 \%$ of German vegan women consume under the recommended iron intake of 18 mg per day, of which $40 \%$ were considered iron deficient based on serum ferritin levels. Researchers did mention that the poor iron status may have been due to the lack of iron fortification of foods, which is not common in Germany (Waldmann, Koschizke, Leitzmann, \& Hahn, 2004).

Hematological values indicating iron status among vegetarians and nonvegetarians also differ in previous studies. Swedish adolescent girls consuming 6 to $27 \mathrm{mg}$ of iron per day, showed low serum ferritin levels among 13.9\% of the girls (Samuelson et al., 1996). Another study looking at young females found median iron intake to be $11.2 \mathrm{mg}$, with $29 \%$ of lacto-ovo-vegetarians, $44 \%$ of semi-vegetarians, and $17 \%$ of nonvegetarians having low iron stores (Donovan \& Gibson, 1995). Thus, the type of diet consumed does affect individual iron status. As expected, values of serum ferritin and hemoglobin were found to be significantly lower for iron deficient women compared with iron replete women (Patterson et al., 2001). Interesting aspects of this study included that the intake data was self-reported, participants may have used iron supplement three months prior to beginning the study, and that phytate intake was significantly higher among the irondeficient women (Patterson et al., 2001). Hematological values indicated that hemoglobin, hematocrit, MCV, MCHC, white blood cells, neutrophils, and serum ferritin in vegetarians were significantly lower than nonvegetarians from Thailand. These results may be due to high intakes of inhibitor of iron absorption for vegetarians (Pongstaporn \& Bunyaratavej, 1999). 
Many studies including this research project assess iron status by comparing iron intake with serum ferritin in vegetarians and nonvegetarians. Among current research, an Australian study found that vegans had higher mean daily intake of iron (22.9 mg per day) compared to lacto-ovo-vegetarians (20.4 mg per day), and nonvegetarian (15.8 $\mathrm{mg}$ per day). With respect to serum ferritin, lacto-ovo-vegetarians $(64 \mathrm{ng} / \mathrm{mL}, \mathrm{p}<0.001)$ and vegans $(65 \mathrm{ng} / \mathrm{mL}, \mathrm{p}<0.05)$ were significantly lower compared to nonvegetarians $(121$ $\mathrm{ng} / \mathrm{mL}$ ). Therefore, even though vegetarians had higher iron intake, their iron status was significantly lower (Wilson \& Ball, 1999). Similar results were found in Buddhist female vegetarians (Shaw et al., 1995), healthy male Australian vegetarians (Due et al., 2000), and in New Zealand vegetarians and vegans (Alexander et al., 1994). A study in Taiwan found that nonvegetarian females had significantly higher iron intake and significantly higher mean plasma ferritin concentration compared to vegetarians (Huang et al., 1999). However, in this study more vegetarian females were considered anemic based on abnormal biochemical indices of iron status. Researchers believed the impaired iron status in vegetarian females might be due to menstrual iron losses; however no information was given on smoking or the influence of supplements on the hematological values (Huang et al., 1999).

Other recent studies did not find statistically significant values among iron intake and hematological values when examining iron status of vegetarians and nonvegetarians. A study conducted at Loma Linda University in California found no significant difference between mean iron intake of female vegans $(17.6 \mathrm{mg} /$ day) and nonvegetarians (15.3 $\mathrm{mg} /$ day), or with mean serum ferritin concentrations between vegans $(27 \mu \mathrm{g} / \mathrm{L})$ and nonvegetarians (22 $\mu \mathrm{g} / \mathrm{L})$ (Haddad et al., 1999). However, values indicate that vegans 
had higher iron intakes with higher ferritin concentrations. Researchers in this study as well as others mention that supplement use was recorded with no mention of the effects on the results (Ball \& Bartlett, 1999; Haddad et al., 1999; Harman \& Parnell, 1998). Thus, lack of significance in these results may have been skewed by the intake of iron through supplements. Other studies found similar results of no significant difference among iron intake and/or serum ferritin values (Ball \& Bartlett, 1999; Harman \& Parnell, 1998; Hunt \& Roughead, 1999; Obeid et al., 2002). One study believed it may have been due to the lack of fortified cereals in the diet and the use of oral contraceptives by some of the participants (Hunt \& Roughead, 1999). Where other researchers believe the low values of serum ferritin could be due to menstrual blood loss (Harman \& Parnell, 1998). Ball \& Bartlett (1999) believed that the reason for vegetarians having lower iron stores probably reflects the interplay of other dietary factors including vitamin C. Larsson \& Johansson (2002) believe insufficient iron status is a female rather than a vegan problem. Wells et al. (2003) believe men during a period of resistance training, who consume a beef-containing diet, have an increased hematological profile. Thus, the consumption of heme iron and the influence of the MPF factor may benefit the iron status of individuals. Another study that found no significant difference between iron intakes of vegetarian and nonvegetarian infants concluded that there is a weak association between meat intake with iron and hemoglobin (Talyor, Redworth, \& Morgan, 2004), suggesting a positive role for red meat and the nonvegetarian diet (Talyor et al., 2004). There was also no significant difference in the iron intakes of vegetarian and nonvegetarian children (Thane $\&$ Bates, 2000). However, serum ferritin concentrations were lower in vegetarians and significantly lower in younger vegetarians compared to nonvegetarians. Researchers 
concluded that low serum ferritin levels indicate reduced iron stores and are an early reflection of iron deficiency (Thane \& Bates, 2000). As evidenced by these studies, iron status and hematological values can be analyzed to determine the iron status of vegetarians and nonvegetarians.

In review, marginal iron status has been found to be a potential problem in women, especially those consuming a vegetarian diet (Haddad, et al., 1999). Also, that the beneficial effects of the vegetarian diet need to be evaluated in light of the potential harm which may arise from iron deficiencies (Obeid et al., 2002). The type of iron consumed (heme or nonheme iron), the amount of iron enhancers (vitamin C and MFP factor) and inhibitors (calcium, phosphate, and Tannins) consumed, and the other factors influencing iron absorption (oral contraceptives, menstruation, vitamin and mineral intake) play a role on the iron status of vegetarians and nonvegetarians. Based on lab values including hemoglobin, serum iron, total iron binding capacity, transferrin saturation, and serum ferritin an individuals stage of iron balance can be determined (Fairweather-Tait, 2004; Herbert, 1992; Mahan \& Escott-Stump, 2004; U. S. NLM \& NIH, 2007). Due to the at risk population of women vegetarians at Cal Poly State Univerity a study was conducted. The hypothesis was that there is a significant difference between iron intake and hematological values related to iron status between vegetarian and nonvegetarian female students studied. 


\title{
CHAPTER 3
}

\author{
Methods
}

Subjects

Subjects were recruited from a convenience sample of students at California Polytechnic State University (Cal Poly), San Luis Obispo. Information fliers were created by the researcher and posted around campus and in local health food stores to aid with recruitment, see appendix A. Other means of recruitment included, classroom and club announcements, information booths set up in the University Union, by word of mouth, and through e-mails and postings on the internet including www.facebook.com. To participate, individuals had to be female, current Cal Poly students, and between the ages of 18 and 22 years old. Those taking vitamin or mineral supplements, medications (including oral contraceptives), smokers, and pregnant women were excluded. Each individual interested in participating was interviewed and/or asked to complete a questionnaire to determine if they met all of the inclusion criteria. Thirty-nine subjects met the criteria and participated in this study. Among the subjects 19 were self-reported vegetarians and 20 were self-reported nonvegetarians. Vegetarians were defined as those who did not consume meat or fish for approximately one year prior and during the study. Of the vegetarians three followed a vegan diet and one followed an ovovegetarian diet.

Subjects also took part in a study involving vitamin B12 status of vegetarians conducted by graduate student Cindi Small. The research project was pre-approved by the Food Science and Nutrition Department, Research and Graduate Programs, and the Cal Poly Human Subjects Committee. All participants read and signed an informed consent for the use of their confidential information in this research study, appendix B. 


\section{Materials}

\section{Questionnaire}

During an initial meeting, eligible individuals who chose to participate completed a questionnaire and were interviewed regarding the questions on the questionnaire by one of two graduate student researchers, see appendix C. The initial meetings were approximately 30 minutes and most took place in the Cal Poly Kinesiology Lab. Information including age, major, grade level, menstrual cycle, eating out, physical activity, diet type, and previous diagnosis of anemia were asked on the questionnaire created by the researchers. Subjects also completed a food frequency questionnaire,

provided by gradual student researcher Cindi Small, see appendix D. The food frequency inquired into the eating habits of protein sources, starches, fruits and vegetables, dairy products, and fats, oil, and sweets in each individual's diet. The food frequency questionnaire was used to verify and validate classification of each participants self reported diet type.

\section{Anthropometric Measurements}

Anthropometric measurements were taken by the researchers, usually during the initial meeting. In the Kinesiology Lab, weight (without heavy cloths or items such as shoes) and height were measured and recorded on the questionnaire. The measured weight and height were used to calculate the body mass index (BMI). BMI was calculated as weight in kilograms divided by the square of the height in meters $\left(\mathrm{kg} / \mathrm{m}^{2}\right)$.

\section{Dietary Intake}

The initial meeting also included instructions for a three day food record, provided by graduate student researcher Cindi Small, see appendix E. The participants were 
instructed to record all food and fluid consumed over two typical weekdays and one typical weekend day, nonconsecutive. Other instructions included recording time, type, and amount of food consumed, using separate Food Record sheets for each day, recording brand names of food, ingredients, and names of restaurants. Food models were used to demonstrate portion sizes, household measures were discussed, food labels were reviewed and food reference materials were given to each participant to give the participants a better understanding on how to estimate portions of food and fluid consumed. Food reference material was provided by graduate student researcher Cindi Small, see appendix F. Over a period of approximately two weeks, once the Food Records were complete, the researchers communicated with the participants via phone or e-mail to determine a time for the second and final meeting. A research study e-mail was created at nutritionstudy@ hotmail.com to communicate with participants. Food records were reviewed by the researchers together with the participant to ensure that the information had been properly described. An average of each participants three day food record was created by entering the data into the nutritional analysis software program Food Processor SQL Edition Version 9.6.0. The data was used to compare the average consumption of nutrients between vegetarians and nonvegetarians. The nutrients analyzed included the consumption of calories, fat, cholesterol, carbohydrates, sugar, fiber, protein, iron, vitamin $\mathrm{C}$, calcium, phosphorus, caffeine, and water. The program included food items traditionally consumed in the United States. Mixed dishes were often separated into basic food components and participants gave the researchers food labels or detailed descriptions when uncommon foods were consumed. 


\section{Hematological Analysis}

Instructions to obtain a single blood sample were also discussed during the initial meeting, see appendix G. A 12 hour fasting blood sample was drawn during the week prior to each participant's menstrual blood loss period. This was done by a phlebolomist at the Cal Poly Health Center. Participants' blood samples were analyzed by the Cal Poly Lab or by an outside lab in San Luis Obispo. Measures included white blood cells, red blood cells, hemoglobin, hematocrit, mean corpuscular volume, mean corpuscular hemoglobin concentration, red cell diameter width, total protein, albumin, triglyceride, cholesterol, HDL, LDL, total cholesterol/HDL ratio, serum iron, serum ferritin, and total iron binding capacity (TIBC). Transferrin saturation was calculated as serum iron divided by total iron binding capacity multiplied by 100 (transferrin saturation= serum iron/TIBC x100). For participating each participant received personalized analysis of their diet and results of their blood analysis either during or at the conclusion of the research study.

\section{Statistical Analysis}

Data from the participants' questionnaires, food record analysis, and hematological measures were combined into an excel spreadsheet. This researcher collaborated with a statistician working for the University of California at Davis Statistical Laboratory to complete the statistical analysis in this research study. The statistical analysis was carried out using SAS for Windows Version 9.1. Results were considered significant at $\mathrm{p} \leq 0.05$ to reduce the chance of false-positive results. Results were given as means with standard deviations (SD), unless otherwise noted. Nonparametric techniques were used to avoid violations with normal distribution assumptions, due to varying distributions of the 
parameters and small sample size. For demographics and baseline characteristics, the Mann-Whitney Wilcoxon statistical test was used to determine if there were differences among vegetarian and nonvegetarian participants. Correlation analysis of selected nutrient and hematological parameters used Spearman Rank Correlation statistical test for associations. Spearman Rank Correlation is a nonparametric version, used to avoid issues with distributional assumptions. Fisher's Exact statistical test was used for associations between vegetarians and nonvegetarians. This included associations with the percent of vegetarians versus nonvegetarians meeting the Recommended Dietary Allowance and Estimated Average Requirement for iron intake, and the different hematological cut off values determining iron status. 


\section{CHAPER 4}

Results

To assess the iron status of vegetarians versus nonvegetarians in this research study the following were analyzed: subject characteristics and demographics obtained by the questionnaire, average dietary intake from the three day food records, hematological analysis from the blood sample, and relationships among dietary intake and hematological analysis.

\section{Subject Characteristics and Demographics}

Subject characteristic and demographic information from the initial questionnaire included the following. Undergraduate participants majoring in Nutrition, Kinesiology, Animal Science, Psychology, Theater, Art, History, Liberal Studies, Political Science, Forestry, Statistics, Mechanical Engineering, Biology, Architecture, Social Sciences, Business, and Computer Science. There were four nonvegetarians and three vegetarians that either had or suspect they had anemia in the past. The number of individuals who ate out for some or most of their meals was similar between the two groups, with only one nonvegetarian never eating out. The nonvegetarian participants were older in age at a mean of 20.65 (SD 1.04) years compared to the vegetarians at a mean age of 19.68 (SD 1.57) years $(\mathrm{p}=0.05)$. Height for the two groups were similar, with a mean height of 65.32 (SD 3.42) inches for nonvegetarians and mean height of 65.30 (SD 2.63) inches for vegetarians $(\mathrm{p}=0.68)$. Weight and body mass index $(\mathrm{BMI})$ for the vegetarians were lower at a mean of 135.40 (SD 23.52) pounds and 22.53 (SD 4.06) BMI compared to nonvegetarians with a mean weight of 144.30 (SD 32.77) pounds and 23.75 (SD 4.55) BMI. Both groups BMI were within the normal range of BMI 18.5-24.9. Differences 
were not significant between vegetarians and nonvegetarians for weight $(\mathrm{p}=0.38)$ or BMI $(\mathrm{p}=0.45)$. Comparisons of the baseline demographics for the participants are presented with means and standard deviations in Table 6.

Table 6. Demographics of Participants

\begin{tabular}{|l|r|c|r|c|l|}
\hline & \multicolumn{2}{|c|}{$\begin{array}{c}\text { Nonvegetarians } \\
(\mathrm{n}=20)\end{array}$} & \multicolumn{2}{c|}{$\begin{array}{c}\text { Vegetarians } \\
(\mathrm{n}=19)\end{array}$} & \\
\hline & Mean & SD* $(+/-)$ & Mean & SD $(+/-)$ & p-value $\dagger$ \\
\hline Age (years) & 20.65 & 1.04 & 19.68 & 1.57 & 0.05 \\
\hline Height (inches) & 65.32 & 3.42 & 65.30 & 2.63 & 0.68 \\
\hline Weight (pounds) & 144.30 & 32.77 & 135.40 & 23.52 & 0.38 \\
\hline BMI (kg/m²) & 23.75 & 4.55 & 22.53 & 4.06 & 0.45 \\
\hline
\end{tabular}

* Standard Deviation. $\dagger$ Significance level. Significant at $\mathrm{p} \leq 0.05$.

A similar number of vegetarian and nonvegetarian participants exercised at an activity level of heavy (example: soccer) and moderate (example: tennis). There were slightly more nonvegetarians who exercised light (example: golf) and very light (example: household chores) compared to vegetarians, however differences were not significant $(\mathrm{p}=0.92)$.

\section{Dietary Intake}

Dietary intake data obtained from the three day food records were used to compare nutrient consumption of vegetarians verses nonvegetarians. Vegetarians had higher consumption of dietary fiber, soluble fiber, and monounsaturated fat compared to nonvegetarians, however differences were not significantly different. Nonvegetarians had a significantly higher intake of protein at 76.99 (SD 24.93) grams per day compared to vegetarians at 58.73 (SD 29.10) grams per day ( $\mathrm{p}=0.01)$. Although not significant, nonvegetarians had a higher density in grams of food consumed, along with higher intake of calories, calories from fat, calories from saturated fat, fat intake, polyunsaturated fat, saturated fat, trans fatty acids, cholesterol, carbohydrates, total sugars, caffeine, and water 
consumption compared to vegetarians. There was no significant difference between iron consumption; however nonvegetarians had higher iron intakes at 16.82 (SD 6.36) $\mathrm{mg}$ per day compared to vegetarians at 14.84 (SD 7.10) mg per day. Nutrients known to influence iron status including vitamin $\mathrm{C}$, calcium, and phosphorus were higher in the nonvegetarian participants compared to the vegetarian participants. However, dietary fiber and soluble fiber were higher in the vegetarian participants' diets. All nutrients known to influence iron status were not significantly different. The mean intakes, standard deviation, and significance level of the selected nutrients are in Table 7.

Table 7. Selected Daily Nutrient Intakes Vegetarians and Nonvegetarians

\begin{tabular}{|c|c|c|c|c|c|}
\hline \multirow[t]{2}{*}{ Nutrient Intake } & \multicolumn{2}{|c|}{$\begin{array}{c}\text { Nonvegetarian } \\
(\mathrm{n}=20)\end{array}$} & \multicolumn{2}{|c|}{$\begin{array}{c}\text { Vegetarian } \\
(\mathrm{n}=19)\end{array}$} & \multirow[b]{2}{*}{$\mathrm{p}$-valuet } \\
\hline & Mean & SD* $(+/-)$ & Mean & $\mathrm{SD}(+/-)$ & \\
\hline Density $(\mathrm{g})$ & 2566.80 & 882.90 & 2290.90 & 871.40 & 0.38 \\
\hline Calories (kcal) & 1917.50 & 513.60 & 1655.80 & 626.90 & 0.13 \\
\hline Calories from Fat (kcal) & 555.80 & 215.50 & 511.70 & 252.70 & 0.58 \\
\hline Calories from Sat Fat (kcal) & 182.40 & 79.87 & 146.70 & 88.41 & 0.19 \\
\hline Fat (g) & 61.76 & 23.94 & 56.96 & 28.18 & 0.60 \\
\hline Monounsaturated fat (g) & 13.14 & 7.10 & 14.95 & 10.19 & 0.76 \\
\hline Polyunsaturated Fat (g) & 6.72 & 4.62 & 7.92 & 4.29 & 0.27 \\
\hline Saturated Fat (g) & 20.27 & 8.87 & 16.30 & 9.82 & 0.20 \\
\hline Trans fatty acids (g) & 0.22 & 0.37 & 0.66 & 0.74 & 0.41 \\
\hline Cholesterol (mg) & 176.10 & 89.79 & 154.40 & 178.50 & 0.11 \\
\hline Carbohydrates (g) & 268.80 & 83.51 & 238.80 & 91.45 & 0.32 \\
\hline Total Sugars (g) & 94.92 & 37.61 & 80.36 & 42.96 & 0.22 \\
\hline Dietary Fiber (g) & 21.62 & 10.43 & 25.98 & 13.35 & 0.31 \\
\hline Soluble Fiber $(\mathrm{g})$ & 1.69 & 1.37 & 2.45 & 1.53 & 0.12 \\
\hline Protein $(\mathrm{g})$ & 76.99 & 24.93 & 58.73 & 29.10 & 0.01 \\
\hline Iron $(\mathrm{mg})$ & 16.82 & 6.36 & 14.84 & 7.10 & 0.48 \\
\hline Vitamin C (mg) & 129.90 & 58.52 & 128.60 & 153.20 & 0.10 \\
\hline Calcium (mg) & 961.50 & 330.50 & 903.40 & 447.60 & 0.35 \\
\hline Phosphorus (mg) & 763.00 & 246.10 & 662.80 & 293.70 & 0.27 \\
\hline Caffeine (mg) & 89.24 & 72.70 & 58.69 & 43.54 & 0.39 \\
\hline Water $(\mathrm{g})$ & 1853.70 & 764.00 & 1629.70 & 797.00 & 0.35 \\
\hline
\end{tabular}

* Standard Deviation. $†$ Significance level. Significant at $\mathrm{p} \leq 0.05$. 
Daily Reference Intake of Iron. The number of vegetarians and nonvegetarians meeting the Recommended Dietary Allowance (RDA) and Estimated Average Requirement (EAR) were compared. The mean iron intake, as discussed earlier, was higher in the nonvegetarian group, however the median value of iron intake differs in that it is higher for the vegetarian group at $16.48 \mathrm{mg}$ per day compared to the nonvegetarian group at $15.66 \mathrm{mg}$ per day. Based on the Dietary Reference Intakes (DRI) for iron in females aged 14 to 18 (from Table 4), the RDA is $15 \mathrm{mg}$ per day and the EAR is $7.9 \mathrm{mg}$ per day. There were seven vegetarian and zero nonvegetarian participants in this age bracket. Of the seven vegetarians, six (85.7\%) were under the RDA and two (28.6\%) were under the EAR for mean intake of iron. Based on the DRI for iron in females aged 19 to 30 years, the RDA is $18 \mathrm{mg}$ per day and the EAR is $8.1 \mathrm{mg}$ per day. There were 12 vegetarians and 20 nonvegetarians in the age bracket. A similar percentage of vegetarians at $66.7 \%(n=8)$ compared to nonvegetarians at $65 \%(n=13)$ were below the RDA for mean iron consumption. There were slightly more nonvegetarians at $10 \%(\mathrm{n}=2)$ compared to vegetarians at $8.3 \%(\mathrm{n}=1)$ under the EAR for mean iron intake. Overall, fewer participants consumed below the Estimated Average Requirement compared to the Recommended Dietary Allowance. The percentage of vegetarians and nonvegetarians below recommended intake levels are presented in Table 8 . 
Table 8. The Percentage of Vegetarians and Nonvegetarians Below Recommended Iron Intake Levels

\begin{tabular}{|l|l|l|l|}
\hline \multicolumn{2}{|c|}{} & Nonvegetarians & Vegetarians \\
\hline \multirow{2}{*}{$<$ RDA $(\%)$} & Females 14-18 years $(\mathrm{n}=7)$ & $(\mathrm{n}=0)$ & $85.7 \%(\mathrm{n}=6)$ \\
\cline { 2 - 4 } & Females 19-30 years $(\mathrm{n}=32)$ & $65 \%(\mathrm{n}=13)$ & $66.7 \%(\mathrm{n}=8)$ \\
\hline \multirow{2}{*}{ EAR $(\%)$} & Females 14-18 years $(\mathrm{n}=7)$ & $(\mathrm{n}=0)$ & $28.6 \%(\mathrm{n}=2)$ \\
\cline { 2 - 4 } & Females 19-30 years $(\mathrm{n}=32)$ & $10 \%(\mathrm{n}=2)$ & $8.3 \%(\mathrm{n}=1)$ \\
\hline
\end{tabular}

Note. Percentages for nonvegetarian females aged 14 to 18 years were not determined because there were no participants in this age bracket.

\section{Hematological Analysis}

Selected baseline hematological measures were compared between vegetarian and nonvegetarian participants. Vegetarians had significantly higher albumin $(\mathrm{p}=0.02)$, mean corpuscular hemoglobin concentration $(\mathrm{MCHC})(\mathrm{p}=0.04)$, and high density lipoprotein cholesterol (HDL) $(\mathrm{p}=0.02)$ compared to nonvegetarians. The vegetarians also had higher red cell diameter width (RDW) compared to the nonvegetarians but the differences were not statistically significant. The nonvegetarians had significantly higher hematocrit $(\mathrm{p}=0.03)$, total protein $(\mathrm{p}=0.02)$, low density lipoproteins cholesterol (LDL) $(\mathrm{p}=0.03)$, and total cholesterol/HDL ratio $(\mathrm{p}=0.002)$ compared to vegetarians. Nonvegetarians had higher values of white blood cells, red blood cells, hemoglobin, mean corpuscular volume (MCV), triglycerides, and cholesterol compared to vegetarians, however not significantly different. Iron status indicators revealed serum iron, serum ferritin, transferrin saturation percentage, and total iron binding capacity to be higher for nonvegetarians compared to vegetarians, however there was no significant different between the two groups. Selected hematological measures with means, standard deviations, and significance value for vegetarians and nonvegetarians are in Table 9. 
Table 9. Selected Hematological Measure for Vegetarians and Nonvegetarians

\begin{tabular}{|c|c|c|c|c|c|}
\hline & \multicolumn{2}{|c|}{ Nonvegetarian } & \multicolumn{2}{|c|}{ Vegetarian } & \\
\hline & Mean & $\mathrm{SD}^{*}(+/-)$ & Mean & $\mathrm{SD}(+/-)$ & p-value $\dagger$ \\
\hline $\begin{array}{l}\text { White Blood Cells } \\
\text { (thousand cells/mcL) }\end{array}$ & 6.19 & 1.21 & 5.37 & 1.21 & 0.08 \\
\hline $\begin{array}{l}\text { Red Blood Cells } \\
\text { (million cells/mcL) }\end{array}$ & 4.42 & 0.23 & 4.38 & 0.41 & 0.90 \\
\hline Hemoglobin $(\mathrm{Hgb})(\mathrm{g} / \mathrm{dL})$ & 13.39 & 0.76 & 12.94 & 1.19 & 0.19 \\
\hline Hematocrit (Hct) (\%) & 40.09 & 2.09 & 38.16 & 3.17 & 0.03 \\
\hline $\begin{array}{l}\text { Mean corpuscular } \\
\text { volume }(\mathrm{MCV})(\mathrm{fl})\end{array}$ & 90.81 & 2.99 & 87.58 & 6.53 & 0.08 \\
\hline $\begin{array}{l}\text { Mean corpuscular } \\
\text { hemoglobin concentration } \\
(\mathrm{MCHC})(\mathrm{g} / \mathrm{dL})\end{array}$ & 33.39 & 0.50 & 33.90 & 1.15 & 0.04 \\
\hline $\begin{array}{l}\text { Red cell diameter width } \\
(\text { RDW) }(\%)\end{array}$ & 12.23 & 0.55 & 12.77 & 1.96 & 0.55 \\
\hline Total Protein (g/dL) & 7.39 & 0.30 & 7.12 & 0.36 & 0.02 \\
\hline Albumin (g/dL) & 4.14 & 0.27 & 4.35 & 0.23 & 0.02 \\
\hline Triglyceride (mg/dL) & 72.50 & 32.90 & 70.00 & 29.18 & 0.94 \\
\hline Cholesterol (mg/dL) & 153.20 & 20.58 & 150.50 & 20.43 & 0.72 \\
\hline HDL (mg/dL) & 54.30 & 14.30 & 65.05 & 11.06 & 0.02 \\
\hline LDL (mg/dL) & 84.35 & 14.44 & 71.42 & 18.30 & 0.03 \\
\hline Total Cholesterol/HDL Ratio & 2.94 & 0.52 & 2.37 & 0.48 & 0.002 \\
\hline Serum Iron $(\mu \mathrm{g} / \mathrm{dL})$ & 102.30 & 46.72 & 81.47 & 35.58 & 0.12 \\
\hline Serum Ferritin (ng/mL) & 27.75 & 18.01 & 23.16 & 15.54 & 0.47 \\
\hline Transferrin Saturation (\%) & 28.85 & 15.17 & 23.10 & 11.31 & 0.24 \\
\hline $\begin{array}{l}\text { Total Iron Binding Capacity } \\
(\mu \mathrm{g} / \mathrm{dL})\end{array}$ & 374.60 & 62.29 & 366.50 & 47.81 & 0.57 \\
\hline
\end{tabular}

* Standard deviation. $\dagger$ Significance level. Significant at $\mathrm{p} \leq 0.05$.

Serum Ferritin. A higher percentage of nonvegetarians were within the normal range of serum ferritin $(40-160 \mathrm{ng} / \mathrm{mL})$ at $25 \%$ compared to $10.5 \%$ for vegetarians. When looking at cut off values for serum ferritin, vegetarians had a higher percentage of participants in negative iron balance. Serum ferritin values of $<25 \mathrm{ng} / \mathrm{mL}$, indicating stage I or early negative iron balance, were higher for vegetarians at $52.6 \%$ compared to nonvegetarians at $45 \%$. Serum ferritin values of $<20 \mathrm{ng} / \mathrm{mL}$, indicating stage II or iron depletion were higher for vegetarians at $47.4 \%$ compared to nonvegetarians at $40 \%$. 
Serum ferritin values of $<10 \mathrm{ng} / \mathrm{mL}$, indicating stage III iron deficiency or stage IV iron deficiency anemia, were higher for vegetarians at $21.1 \%$ compared to nonvegetarians at $15 \%$. The frequency distribution of serum ferritin for vegetarians and nonvegetarians are shown in Figure 1.

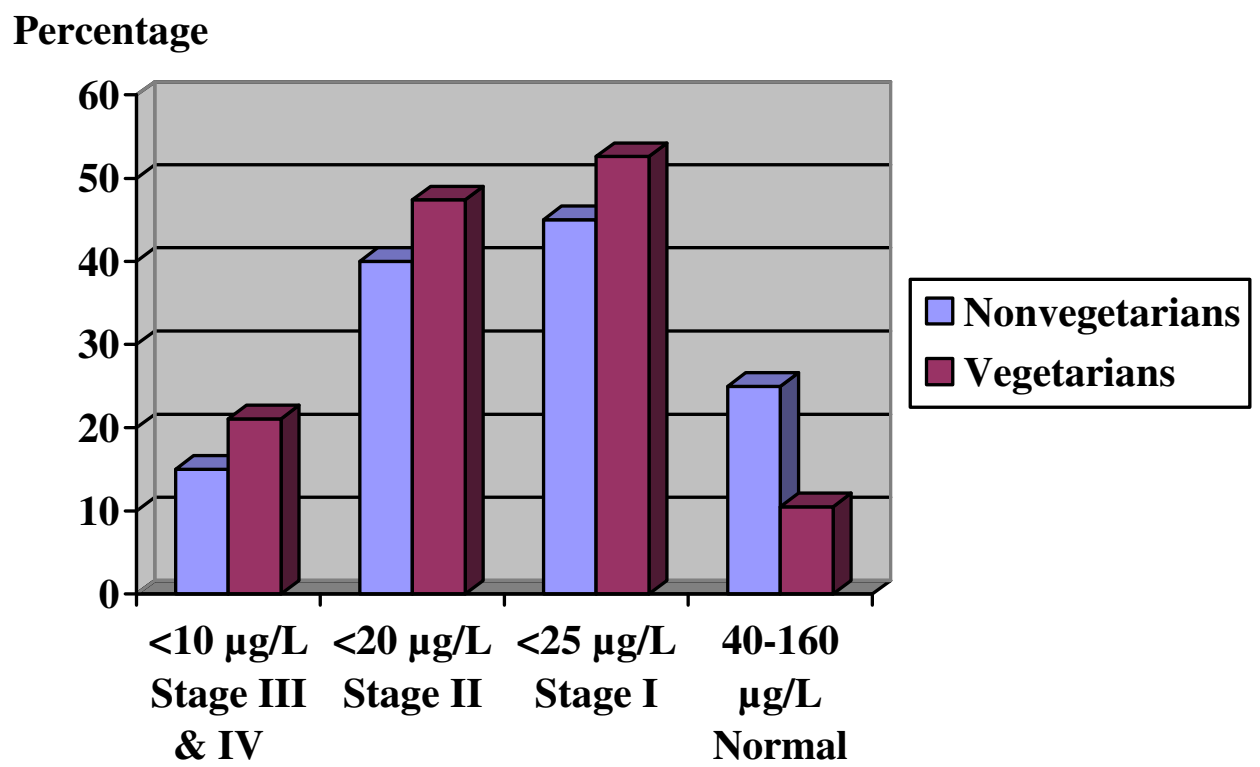

Serum Ferritin

Figure 1. Frequency Distribution of Serum Ferritin in Vegetarians and Nonvegetarians. Modified From Donovan et al., 1995; Shaw et al., 1995.

Iron Balance. Serum ferritin, serum iron, total iron binding capacity (TIBC), and transferrin saturation levels are given for stage I, II, III, and IV negative iron balance, see Table 10. For negative I iron balance there was a significantly higher percentage of vegetarians with serum iron of $>120 \mu \mathrm{g} / \mathrm{dL}$ at $94.7 \%$ compared to nonvegetarians at $65 \%$ $(\mathrm{p}=0.03)$. Although not significant, there was also a higher percentage of vegetarians with transferrin saturation $>60 \%$ and serum ferritin $<25 \mathrm{ng} / \mathrm{mL}$ compared to nonvegetarians. For negative II iron balance, there was a higher percentage of vegetarians at serum iron $<115 \mu \mathrm{g} / \mathrm{dL}$, serum ferritin $<20$, and a lower percentage of 
vegetarians at total iron binding capacity $>360 \mu \mathrm{g} / \mathrm{dL}$ compared to nonvegetarians. For negative III iron balance, there were a higher percentage of vegetarians at serum iron $<60$ $\mu \mathrm{g} / \mathrm{dL}$, transferrin saturation $<15 \%$, serum ferritin $<10 \mathrm{ng} / \mathrm{mL}$, and a lower percentage of vegetarians with total iron binding capacity of $>390 \mu \mathrm{g} / \mathrm{dL}$ compared to nonvegetarians.

For negative IV iron balance, vegetarians had a higher percentage of participants at serum iron $<40 \mu \mathrm{g} / \mathrm{dL}$ and total iron binding capacity of $>410 \mu \mathrm{g} / \mathrm{dL}$ compared to nonvegetarians. Comparisons of the percentage of vegetarians and nonvegetarians in negative II, III, and IV iron balance were not significantly different.

Table 10. The Percentage of Vegetarians and Nonvegetarians Above and Below Cut-off Points for Selected Iron Status Indices

\begin{tabular}{|c|c|c|c|c|c|}
\hline $\begin{array}{l}\text { Stage } \\
\text { Variable }\end{array}$ & & $\begin{array}{l}\text { Cut-off } \\
\text { Value }\end{array}$ & Nonvegetarians & Vegetarians & $\mathrm{p}$-value $\dagger$ \\
\hline \multirow{4}{*}{$\begin{array}{l}\text { Negative } \\
\text { I }\end{array}$} & Iron* & $<120$ & $65 \%(n=13 / 20)$ & $94.7 \%(n=18 / 19)$ & 0.03 \\
\hline & TIBC $+\dagger$ & $>360$ & $60 \%(n=12 / 20)$ & $52.6 \%(\mathrm{n}=10 / 19)$ & 0.87 \\
\hline & Saturation§ & $<30$ & $50 \%(\mathrm{n}=10 / 20)$ & $68.4 \%(n=13 / 19)$ & 0.11 \\
\hline & Ferritin** & $<25$ & $45 \% \quad(n=9 / 20)$ & $52.6 \%(\mathrm{n}=10 / 19)$ & 0.44 \\
\hline \multirow{4}{*}{$\begin{array}{l}\text { Negative } \\
\text { II }\end{array}$} & Iron & $<115$ & $65 \%(\mathrm{n}=13 / 20)$ & $84.2 \%(n=16 / 19)$ & 0.16 \\
\hline & TIBC & $>360$ & $60 \%(n=12 / 20)$ & $52.6 \%(n=10 / 19)$ & 0.87 \\
\hline & Saturation & $<30$ & $50 \%(\mathrm{n}=10 / 20)$ & $68.4 \%(n=13 / 19)$ & 0.11 \\
\hline & Ferritin & $<20$ & $40 \% \quad(n=8 / 20)$ & $47.4 \% \quad(n=9 / 19)$ & 0.44 \\
\hline \multirow{4}{*}{$\begin{array}{l}\text { Negative } \\
\text { III }\end{array}$} & Iron & $<60$ & $25 \% \quad(n=5 / 20)$ & $26.3 \% \quad(n=5 / 19)$ & 0.61 \\
\hline & TIBC & $>390$ & $35 \% \quad(\mathrm{n}=7 / 20)$ & $21.1 \% \quad(n=4 / 19)$ & 0.95 \\
\hline & Saturation & $<15$ & $20 \% \quad(n=4 / 20)$ & $21.1 \% \quad(n=4 / 19)$ & 0.62 \\
\hline & Ferritin & $<10$ & $15 \% \quad(\mathrm{n}=3 / 20)$ & $21.1 \% \quad(n=4 / 19)$ & 0.47 \\
\hline \multirow{4}{*}{$\begin{array}{l}\text { Negative } \\
\text { IV }\end{array}$} & Iron & $<40$ & $10 \% \quad(\mathrm{n}=2 / 20)$ & $21.1 \% \quad(n=4 / 19)$ & 0.31 \\
\hline & TIBC & $>410$ & $15 \% \quad(\mathrm{n}=3 / 20)$ & $21.1 \% \quad(n=4 / 19)$ & 0.47 \\
\hline & Saturation & $<15$ & $20 \% \quad(n=4 / 20)$ & $21.1 \% \quad(n=4 / 19)$ & 0.62 \\
\hline & Ferritin & $<10$ & $15 \% \quad(\mathrm{n}=3 / 20)$ & $21.1 \% \quad(n=4 / 19)$ & 0.47 \\
\hline
\end{tabular}

$*$ Serum iron $(\mu \mathrm{g} / \mathrm{dL}) . \dagger \mathrm{p}$-value significant at $\mathrm{p} \leq 0.05 \S$ Transferrin saturation $(\%)$.

$* *$ Serum ferritin $(\mathrm{ng} / \mathrm{mL})$. $\dagger \dagger$ Total iron binding capacity $(\mu \mathrm{g} / \mathrm{dL})$.

Note. Information based on data from Table 3.

Modified from Brussaard et al., 1997. 


\section{Relationship Among Dietary Intake and/or Hematological Analysis}

Correlations among selected nutrients and/or hematological parameters from all participants ( $\mathrm{n}=39$ ) were analyzed to determine positive or negative associations using Spearmen Rank Correlation test for association. The dietary variables for which correlations were preformed include iron intake with vitamin $\mathrm{C}$ and calcium intake, and vitamin $\mathrm{C}$ intake with calcium intake. Of the selected nutrient comparisons, only iron intake with vitamin $\mathrm{C}$ intake $(\mathrm{r}=0.56, \mathrm{p}=0.0002)$, and calcium intake with vitamin $\mathrm{C}$ intake $(\mathrm{r}=0.38, \mathrm{p}=0.02)$ correlated significantly with a positive association. Thus, iron and calcium intake increased as vitamin $\mathrm{C}$ intake increased. When looking at nutrient intake of iron compared to hematological values, there was a nonsignificant negative association with serum iron and total iron binding capacity. Results indicate that as iron intake increased, serum iron and total iron binding capacity decreased. Iron intake had a nonsignificant positive association with hemoglobin $(\mathrm{r}=0.30, \mathrm{p}=0.06)$ and serum ferritin $(\mathrm{r}=0.28, \mathrm{p}=0.09)$. Thus, as iron intake increased hemoglobin and serum ferritin levels also increased. For vitamin $\mathrm{C}$ and calcium, there was a nonsignificant positive association with serum ferritin and hemoglobin. Vitamin $\mathrm{C}$ had a negative and calcium had a positive nonsignificant association with total iron binding capacity. Therefore, as vitamin $\mathrm{C}$ intake increased then TIBC decreased, and as calcium intake increased TIBC would increased. The opposite was found for serum iron and transferrin saturation, vitamin $\mathrm{C}$ intake had a nonsignificant positive associations and calcium intake had a nonsignificant negative association. Thus, as vitamin $\mathrm{C}$ intake increased serum iron and 
transferrin saturation also increased, and as calcium intake increased serum iron and transferrin saturation decreased.

Correlations between hematological values were analyzed. Positive or negative correlations (r-value) and the significant correlations between dietary intake and/or hematological values (p-value) found in this study, are shown in Table 11.

Table 11. Correlations between Dietary Intakes and/or Hematological Values

\begin{tabular}{|c|c|c|c|c|c|c|c|}
\hline & $\begin{array}{l}\text { Vitamin C } \\
\text { Intake }\end{array}$ & $\begin{array}{l}\text { Calcium } \\
\text { Intake }\end{array}$ & $\begin{array}{l}\text { Serum } \\
\text { Ferritin }\end{array}$ & $\begin{array}{l}\text { Serum } \\
\text { Iron }\end{array}$ & \begin{tabular}{|l|} 
Total Iron \\
Binding \\
Capacity \\
\end{tabular} & $\begin{array}{l}\text { Transferrir } \\
\text { Saturation }\end{array}$ & Hemoglobin \\
\hline $\begin{array}{l}\text { Iron } \\
\text { Intake }\end{array}$ & $\begin{array}{l}\mathrm{r}^{*}=0.56 \\
\mathrm{p} \dagger=0.0002\end{array}$ & $\begin{array}{l}\text { No Data } \\
\text { Obtained }\end{array}$ & $\begin{array}{l}r=0.28 \\
p=0.09\end{array}$ & $\begin{array}{l}r=-0.07 \\
p=0.69\end{array}$ & $\begin{array}{l}r=-0.04 \\
p=0.83\end{array}$ & $\begin{array}{l}\text { No Data } \\
\text { Obtained }\end{array}$ & $\begin{array}{l}r=0.30 \\
p=0.06\end{array}$ \\
\hline $\begin{array}{l}\text { Vitamin C } \\
\text { Intake }\end{array}$ & 1.00 & $\begin{array}{l}r=0.38 \\
p=0.02\end{array}$ & $\begin{array}{l}r=0.23 \\
p=0.16\end{array}$ & $\begin{array}{l}r=0.05 \\
p=0.76\end{array}$ & $\begin{array}{l}r=-0.08 \\
p=0.62\end{array}$ & $\begin{array}{l}r=0.02 \\
p=0.90\end{array}$ & $\begin{array}{l}r=0.15 \\
p=0.37\end{array}$ \\
\hline $\begin{array}{l}\text { Calcium } \\
\text { Intake }\end{array}$ & & 1.00 & $\begin{array}{l}r=0.03 \\
p=0.87\end{array}$ & $\begin{array}{l}r=-0.13 \\
p=0.42\end{array}$ & $\begin{array}{l}r=0.005 \\
p=0.98\end{array}$ & $\begin{array}{l}r=-0.09 \\
p=0.57\end{array}$ & $\begin{array}{l}r=0.01 \\
p=0.94\end{array}$ \\
\hline $\begin{array}{l}\text { Serum } \\
\text { Ferritin }\end{array}$ & & & 1.00 & $\begin{array}{l}\mathrm{r}=0.51 \\
\mathrm{p}=0.001\end{array}$ & $\begin{array}{l}r=-0.63 \\
p<0.0001\end{array}$ & $\begin{array}{l}r=0.61 \\
p<0.0001\end{array}$ & $\begin{array}{l}r=0.31 \\
p=0.051\end{array}$ \\
\hline $\begin{array}{l}\text { Serum } \\
\text { Iron }\end{array}$ & & & & 1.00 & $\begin{array}{l}r=-0.41 \\
p=0.01\end{array}$ & $\begin{array}{l}\mathrm{r}=0.95 \\
\mathrm{p}<0.0001\end{array}$ & $\begin{array}{l}\mathrm{r}=0.41 \\
\mathrm{p}=0.01\end{array}$ \\
\hline $\begin{array}{l}\text { Total Iron } \\
\text { Binding } \\
\text { Capacity } \\
\end{array}$ & & & & & 1.00 & $\begin{array}{l}r=-0.63 \\
p<0.0001\end{array}$ & $\begin{array}{l}r=-0.08 \\
p=0.63\end{array}$ \\
\hline $\begin{array}{l}\text { Transferrin } \\
\text { Saturation }\end{array}$ & & & & & & 1.00 & $\begin{array}{l}r=0.37 \\
p=0.02\end{array}$ \\
\hline
\end{tabular}

* Correlation value: $r$-value is positive association or (-) negative association.

$\dagger$ Significance level. Significant at $\mathrm{p} \leq 0.05$.

Note. Two correlations not obtained in error. Serum Iron and Total Iron Binding Capacity used in Transferrin Saturation calculation, see methods for details.

Findings indicated serum ferritin to have a significant positive correlation with serum iron $(\mathrm{r}=0.51, \mathrm{p}=0.001)$ and transferrin saturation $(\mathrm{r}=0.61, \mathrm{p}<0.0001)$. Serum iron also had a significant negative correlation with total iron binding capacity $(r=-0.62, p<0.0001)$. 
Thus, as ferritin increased serum iron and transferrin saturation also increased and TIBC decreased. For hemoglobin levels, there was a nonsignificant positive association with serum ferritin and a nonsignificant negative association with total iron binging capacity. Hemoglobin was found to have significant positive associations with serum iron ( $\mathrm{r}=0.41$, $\mathrm{p}=0.01)$ and transferrin saturation $(\mathrm{r}=0.37, \mathrm{p}=0.02)$. For total iron binding capacity there was a significant negative correlation with serum iron $(r=-0.41, p=0.01)$, which indicate that as serum iron levels increased total iron binding capacity levels decreased. 


\section{CHAPTER 5}

Discussion

The objective of this study was to compare the nutrient and hematological values related to iron status in female university students following a vegetarian versus nonvegetarian diet.

\section{Subject Characteristics and Demographics}

Although many studies have compared nutrient intakes and selected hematological values in vegetarians and nonvegetarians, this cross-sectional study was unique in that strict inclusion criteria were used to assess the iron status of vegetarians. Individuals in this study had similar baseline characteristics and demographics with the exception of vegetarian diet status.

\section{Dietary Intake}

This study used a three day food record, which has been suggested to be sufficient and used the most for dietary assessments of differences between groups (Huang et al., 1999; Thane \& Bates, 2000). Based on this study's average of the three day food record, many positive attributes were seen in the vegetarian diet. Positive attributes in the vegetarian diet included having higher monounsaturated fat intake, lower intake of calories from fat, calories from saturated fat, trans fatty acid, cholesterol, total sugar, and caffeine. Dietary fiber and soluble fiber were also higher in the vegetarian diet; however it may be a concern due the inhibiting effects fiber has on iron absorption (Harman \& Parnell, 1998; Pongstaporn \& Bunyaratavej, 1999). Other concerns for the participants on the vegetarian diet included having lower mean intakes of calories, protein, calcium, phosphorus, vitamin $\mathrm{C}$, iron, and water compared to nonvegetarians. It is possible that 
some participants may have chosen a vegetarian diet to consume fewer calories than the nonvegetarians for dieting purposes. The level of protein intake was significantly lower in vegetarians at 58.73 grams per day compared to nonvegetarians at 76.99 grams per day, however the amount of protein consumed was above the Recommended Dietary Intake of 46 grams per day (U. S. NLM \& NIH, 2007). Calcium and phosphorus are needed in the body but are inhibitors of iron absorption when eaten with iron rich foods (Hallberg \& Hulthen, 2000), as discussed in the Review of Literature. Both vegetarian intake of calcium (903.4 mg per day) and phosphorus (662.8 $\mathrm{mg}$ per day) of the participants in this thesis research study were lower then the Adequate Intake for calcium (1,000 mg per day) and the Recommended Dietary Allowance of phosphorus (700 mg per day), for female aged 19 to 30 years (U. S. NLM \& NIH, 2007). There is a concern with vegetarians consuming less vitamin $\mathrm{C}$ compared to nonvegetarians due to the enhancing effect vitamin C has on iron absorption (Mahan \& Escott-Stump, 2004). However, in this thesis research study the vegetarian's vitamin C intake at $128.6 \mathrm{mg}$ per day was well above the Recommened Dietary Allowance of $75 \mathrm{mg}$ per day (U. S. NLM \& NIH, 2007).

As discussed in the Results, vegetarians had a lower mean intake and a higher median intake of iron compared to nonvegetarians, neither were significantly different. Vegetarian participats mean iron intake ranged from 4.15 to $29.00 \mathrm{mg}$ compared to nonvegetarinas iron intake range from 7.65 to $34.53 \mathrm{mg}$. However, median intake of iron for the vegetarian participants was $16.48 \mathrm{mg}$ compared to $15.66 \mathrm{mg}$ for nonvegetarins. Even though the results indicate vegetarinas on average ate less iron, the median may indicate the mean is scude due to outliers. Fourteen of the vegetarians and 13 of the nonvegetarians were below their respective Recommended Dietary Allowance of iron for 
age. Also, three of the vegetarians and two of nonvegetarians were below their respective Estimated Average Requirement of iron for age. The Estimated Average Requirement for iron refers to the average assessed level of iron intake in the population (U. S. DHHS, 2005). Therefore, even though a total of five participants were below the Estimated Average Requirement the majority of vegetarians and nonvegetarians had a higher iron intake than the average intake of iron in the general population. Vegetarian's total iron intake may be more adequate in these participants due to the consumption of fortified foods in the diet, as stated buy previous researchers (Mahan \& Escott-Stump, 2004; Whittaker, Tufaro, \& Rader, 2001).

\section{Hematological Analysis}

Based on selected hematological measures in this study, vegetarians had better lipid values with lower triglycerides, cholesterol, LDL, total cholesterol/HDL ratio, and higher HDL values compared to nonvegetarians. Better lipid values in vegetarians support finding of lower mortality for ischemic heart disease (Key et al., 1998). Vegetarians had lower serum iron, total iron binding capacity, transferrin saturation, and serum ferritin, all of which are the indicators of iron status in this study. As discussed in the Review of Literature serum ferritin is the optimal approach to assessing iron status of a population (Cooper \& Zlotkin, 1996; Herbert, 1992; Pongstaporn \& Bunyaratavej, 1999; Shine, 1997). Only $10.5 \%$ of the vegetarians compared to $25 \%$ of the nonvegetarians were at the normal range of serum ferritin. There was a smaller percentage of vegetarians within the normal range of serum ferritin, and a larger percentage of vegetarians at lower levels of serum ferritin (stage I, II, III, IV negative iron balance) compared to nonvegetarians. Based on all indicators of iron status used in this study, there was a greater percentage of 
vegetarians at stage IV negative iron balance. Stage IV iron balance is where iron deficiency anemia occurs (Cooper et al., 2006; Herbert, 1992; Mahan \& Escott-Stump, 2004). Menstrual blood loss could be one possible reason for participants in this study having low iron status, as discussed in the Review of Literature (Alexander et al., 1994; Harvey et al,. 2005; Mahan \& Escott-Stump, 2004). This thesis research study attempted to control for blood loss through menstruation by having participants schedule their blood draw approximately one week prior to their menstrual blood loss period. However, there were five $(25 \%)$ nonvegetarians and five $(26 \%)$ vegetarian participants who stated that they had irregular menstrual cycles and one vegetarian stated that she had been amenorrheic (without menstrual period) for approximately one year.

\section{Relationship Among Dietary Intakes and/or Hematological Analysis}

Correlations between selected nutrient intake and/or hematological measures in this study were presented in the Results. The results found no significant correlation between iron intake and serum ferritin, which was also found by other researchers (Ball \& Bartlett, 1999; Due et al., 2000). However there was a positive association found between the two values. A positive association would mean that as iron intake increased serum ferritin also increased. Iron intake in this study did not take into account the type of iron consumed. All associations between values were expected except for the negative association of iron intake and serum iron, and the positive association of calcium intake with serum ferritin and hemoglobin. As discussed in the Review of Literature, it would be expected that if iron intake increased then serum iron would also increase. However, serum iron is a poor indicator of iron status due to large day-to-day changes, potentially skewing research data (Herbert, 1992; Mahan \& Escott-Stump, 2004). Increased calcium 
intake would be expected to be negatively associated with serum ferritin and hemoglobin due to the inhibiting effects of calcium on iron absorption, as found in other research (Hallberg \& Hulthen, 2000). However, calcium intake in the participants was not at high levels, in fact calcium intake of vegetarians $(903.40 \mathrm{mg}$ ) and nonvegetarians $(961.50 \mathrm{mg})$ were lower than the Adequate Intake of 1,000 mg per day.

Correlations found in the literature that were similar to this thesis research study include serum ferritin and total iron binding capacity negatively correlated (Mahan \& Escott-Stump, 2004). Thus, as serum ferritin decreases it would be expected that total iron binding capacity would increase and provide more transferrin molecules to bind iron, acting as a body regulator to increase iron status. Another similar finding was serum ferritin and its significant positive correlation with transferrin saturation $(\mathrm{p}<0.005)$ (Mahan \& Escott-Stump, 2004; Samuelson et al., 1996). Therefore, in iron deficiency both serum ferritin and transferrin saturation would likely be decreased.

Published correlations related to iron status not found in this thesis research study, include a significant positive correlation between iron intake and hemoglobin concentration ( $\mathrm{r}=0.26, \mathrm{p}=0.005$ ) (Shaw et al., 1995). Another study found that heme iron intake correlated significantly with hemoglobin concentrations, serum ferritin, and transferrin saturation (Thane et al., 2003). Thus, the positive effects heme iron has on iron status warrants more research. Iron intake and vitamin C intake were found to be positively associated with serum iron $(\mathrm{p}<0.04)$ and found to be significantly and negatively associated with total iron binding capacity $(\mathrm{p}<0.02)$ (Donovan \& Gibson, 1995). These results would be expected due to vitamin $C$ enhancing effect on iron absorption. Other correlation values and significant levels that may have been valuable 
to this thesis research include iron intake with calcium intake due to calcium's inhibiting factor on iron absorption, iron intake with transferrin saturation, and phosphorus intake and fiber intake on serum ferritin due to their inhibiting factor on iron absorption.

\section{Iron Intake and Serum Ferritin}

Results from this thesis research study can be compared to similar finding in other studies, shown in Table 12. In this thesis research study, mean iron intake and serum ferritin were higher in nonvegetarians compared to vegetarians. Different results were found in Ball and Barrlett's (1999) study on Australian vegetarian women. They had higher iron intake and significantly lower serum ferritin compare to nonvegetarians ( $\mathrm{p}=0.025)$ (Ball \& Barrlett, 1999). Ball and Barrlett's (1999) study included participants that smoked and used supplements, possibly causing these results. When excluding those participants who used supplements, ferritin was not significantly different between vegetarians and nonvegetarians (Ball \& Barrlett, 1999). Thus, supplement intake may have a positive influence on ferritin levels. In Haung et al. (1999) Taiwanese nonvegetarians had a significantly higher iron intake and higher serum ferritin levels compared to vegetarians. Unlike the United States and Australia, Taiwan does not routinely fortify foods with iron (Ball \& Barrlett, 1999; Haung et al, 1999; Mahan \& Escott-Stump, 2004). Haung et al. (1999) also reported that participants used supplements, which was recorded into the dietary intake; however the impact on serum ferritin was not mentioned (Huang et al., 1999). The opposite was found in a study done by Hadded et al. (1994) in Loma Linda California. The vegan female participants had a nonsignificant higher mean iron intake and serum ferritin levels compared to nonvegetarian participants (Haddad et al., 1999). Supplement uses in participants were 
recorded and possibly aided in the higher iron intake and serum ferritin levels of the vegan participants (Haddad et al., 1999). In Wilson and Ball (1999), Australian male vegans had significantly higher iron intake compared to nonvegetarians (Wilson \& Ball, 1999). Serum ferritin was significantly lower for lacto-ovo-vegetarians $(\mathrm{p}<0.001)$ and vegans $(\mathrm{p}<0.05)$ compared to nonvegetarians (Wilson \& Ball, 1999). There were 22 vegetarian participants who took supplements, with eight lacto-ovo-vegetarians and two nonvegetarians who took iron supplements (Wilson \& Ball, 1999). Thus, supplementation may have aided with iron intake, but the type of iron consumed by the Table 12. Results of Similar Studies on Iron Intake and Serum Ferritin Values of Vegetarians and Nonvegetarians

\begin{tabular}{|c|c|c|c|c|c|c|}
\hline $\begin{array}{c}\text { Reference } \\
\& \\
\text { Location }\end{array}$ & Subjects & Age & $\begin{array}{c}\text { Mean } \\
\text { Iron Intake } \\
(\mathrm{mg})\end{array}$ & $\begin{array}{c}\text { Mean } \\
\text { Serum Ferritin } \\
(\mu \mathrm{g} / \mathrm{L}=\mathrm{ng} / \mathrm{mL})\end{array}$ & Outcome & Limitations \\
\hline $\begin{array}{l}\text { Ball \& } \\
\text { Bartlett, } \\
1999 \\
\text { Australia }\end{array}$ & $\begin{array}{l}\text { Women } \\
50 \mathrm{~V} \\
24 \mathrm{NV}\end{array}$ & \begin{tabular}{|l}
$18-45$ \\
Years
\end{tabular} & $\begin{array}{l}\text { V: } 10.7 \\
N V: 9.9\end{array}$ & $\begin{array}{l}\text { V: } 25 \\
\text { NV: } 45.5 \\
\text { Supp excluded } \\
\text { V: } 24.2\end{array}$ & $\begin{array}{l}\text { Intake not sign. } \\
\text { Ferritin sign. } \\
(\mathrm{p}=0.025) \\
\text { Supp excluded } \\
\text { Ferritin not sign. }\end{array}$ & $\begin{array}{l}\text { Asked about } \\
\text { Supp }(7 \text { V.) \& smoking } \\
\text { Vitamin C higher in V }\end{array}$ \\
\hline $\begin{array}{l}\text { Huang et } \\
\text { al., } 1999 \\
\text { Taiwan }\end{array}$ & $\begin{array}{l}35 \mathrm{~V} \\
(15 \mathrm{M}, 20 \mathrm{~F}) \\
32 \mathrm{NV} \\
(13 \mathrm{M}, 19 \mathrm{~F}) \\
\end{array}$ & \begin{tabular}{|l}
$<40$ \\
Years
\end{tabular} & $\begin{array}{l}V: 21.3 \\
N V: 34.5\end{array}$ & $\begin{array}{l}\mathrm{V}: 17.9 \\
\mathrm{NV}: 40\end{array}$ & $\begin{array}{l}\text { Intake \& } \\
\text { Ferritin sign. }\end{array}$ & $\begin{array}{l}\text { Supp recorded not } \\
\text { included in dietary. } \\
\text { Intake-may have changed } \\
\text { ferritin out come. } \\
\text { No fortification }\end{array}$ \\
\hline $\begin{array}{l}\text { Haddad et } \\
\text { al., } 1999 \\
\text { Loma } \\
\text { Linda, Ca }\end{array}$ & $\begin{array}{l}\text { Vegans } \\
(10 \mathrm{M}, 15 \mathrm{~F}) \\
\mathrm{NV} \\
(10 \mathrm{M}, 10 \mathrm{~F})\end{array}$ & $\begin{array}{l}20-60 \\
\text { Years }\end{array}$ & $\begin{array}{l}\text { F- } \\
\text { Vegans: } 17.6 \\
\text { NV: } 15.3\end{array}$ & $\begin{array}{l}\text { F- } \\
\text { Vegans: } 27 \\
\text { NV: } 22\end{array}$ & \begin{tabular}{|l|} 
F: Intake \& \\
Ferritin not sign. \\
M: Ferritin sign \\
lower in vegan
\end{tabular} & $\begin{array}{l}\text { Supp use } \\
\text { only recorded }\end{array}$ \\
\hline \begin{tabular}{|l|} 
Wilson \& \\
Ball, 1999 \\
Australia
\end{tabular} & $\begin{array}{l}\text { Male } \\
39 \text { LOV } \\
10 \text { Vegans } \\
25 \mathrm{NV}\end{array}$ & $\begin{array}{l}20-50 \\
\text { Years }\end{array}$ & $\begin{array}{l}\text { LOV:20.4 } \\
\text { Vegans: } 22.9 \\
\text { NV: } 15.8\end{array}$ & $\begin{array}{l}\text { LOV: } 64 \\
\text { Vegans:65 } \\
\text { NV: } 121\end{array}$ & $\begin{array}{l}\text { Intake vegans } \\
\text { sign. from NV } \\
\text { Ferritin } \\
\text { LOV }(\mathrm{p}<0.001) \\
\text { Vegan }(\mathrm{p}<0.05) \\
\text { sign. from } \mathrm{NV} \\
\end{array}$ & $\begin{array}{l}22 \mathrm{~V} \text { took supp } \\
\text { with out iron } \\
8 \mathrm{LOV} \& \\
2 \mathrm{NV} \text { took iron supp }\end{array}$ \\
\hline
\end{tabular}

Note. $\mathrm{V}=$ vegetarian. $\mathrm{LOV}=$ lacto-ovo-vegetarian. $\mathrm{NV}=$ nonvegetarian. $\mathrm{M}=$ male $\mathrm{F}=$ female. Sign. $=$ significant difference. Significant at $\mathrm{p} \leq 0.05$

Not Sign. = no significant difference. Supp $=$ supplement 
nonvegetarians may have positively influenced their iron status. The purpose of these research studies are similar to this thesis research study, however this thesis research study may have had better controls by limiting inclusion criteria, possibly proving a better assessment of iron status in vegetarians and nonvegetarians.

\section{Limitations}

Possible limitations of this research study include the use of self reported information on the questionnaire and possible misreporting of food on the three day food record. However, the participants' diet type (vegetarian or nonvegetarian) was verified with the food frequency questionnaire and the three day diet record was reviewed with a researcher. Limitations to the questionnaire and the three day food record include validity and reliability, if this thesis research study were recreated using preciously tested material would be recommended. Other information that would have been helpful to include on the questionnaire are previous blood donations, which may have impacted iron status. Limiting inclusion criteria to females with regular menstrual cycles may eliminate possible inhibiting factors on iron status. This thesis research study tried to control for this by having participants provide lab work one week prior to their menstrual blood loss period, however ten participants had irregular menstruation. The use of nutritional software able to determine amount of heme and nonheme iron consumed for each participant would have been ideal. Another limitation is that the sample size in this study was small with only 39 participants. However, the inclusion criteria were more strict compared to other studies involving vegetarian and nonvegetarian participants. Pooling from multiple university campuses and using both genders would be ideal if this thesis research study was recreated. The participants were from a convenience sample 
instead of a random sample of the population, and may have been more willing to participant if they were in better health. As for the results, they can only be interpreted for the participants in this study due the inclusion criteria and are not representative of all vegetarians and nonvegetarians in the population.

\section{Conclusion}

This researcher concluded that among the female Cal Poly State University student participants, vegetarians were at higher risk of developing negative iron balance compared to nonvegetarians. The null hypothesis was correct in that there was no significant difference between iron intake and hematological values related to iron status between vegetarian and nonvegetarians female students studied. However, the findings showed that vegetarians had lower mean iron consumption, lower consumption of iron absorption enhancing vitamin $\mathrm{C}$, and a high consumption of iron absorption inhibiting phosphorus compared to nonvegetarians. Serum ferritin was also lower in vegetarian participants compared to the nonvegetarian participants, possibly indicating poorer iron status. However, results were not significant and further research is warranted. Female university students following a vegetarian diet should be educated on iron deficiency anemia and prevention of iron depletion. Educational topics on ways vegetarians can increase their iron status include consuming more iron rich foods with a vitamin $\mathrm{C}$ rich

food. Vegetarians should be counseled to avoid calcium and phosphorus rich foods when consuming iron rich foods. Further research involving the same inclusion criteria, limiting blood donation prior to participating, having a larger number of vegetarians and nonvegetarians participants, and having all participants with regular menstrual cycles 
may be needed to more accurately assess the iron status of vegetarians and nonvegetarians in this population. 


\section{LIST OF REFERNCES}

Alexander, D., Ball, \& M. J., Mann, J. (1994). Nutrient intake and haematological status of vegetarians and age-sex matched omnivores. European Journal of Clinical Nutrition. 48. 538-546.

Baech, S. B., Hansen, M., Bukhave, K., Jensen, M., Sorensen, S. S., Kristensen, L. et al. (2003). Nonheme-iron absorption from a phytate-rich meal is increased by the addition of small amounts of pork meat. The American Journal of Clinical Nutrition. 77. 173-179.

Ball, M. J., \& Bartlett, M. A. (1999). Dietary intake and iron status of Australian vegetarian women. The American Journal of Clinical Nutrition. 70. 353-358.

Barr, S. I., \& Chapman, G. E. (2002). Perceptions and practices of self-defined current vegetarian, former vegetarian, and non-vegetarian women. Journal of the American Dietetic Association. 102. 3. 354-361.

Beard, J. L. (2001). Iron biology in immune function, muscle metabolism and neuronal functioning. The Journal of Nutrition. 131. 568-580.

Bedford, J. L., \& Barr, S. I. (2005). Diets and selected lifestyle practices of self-defined adult vegetarians for a population-based sample suggest they are more 'health conscious.' International Journal of Behavioral Nutrition and Physical Activity. 2. 4. Retrieved April 26, 2006, from http://www.ijbnpa.org/content/2/1/4.

Bingham, S. A, Welch, A. A., McTaggart, A., Mulligan, A. A., Runswich, S. A., Luben, R., et al. (2001). Nutritional methods in the European Prospective Investigation of Cancer in Norfolk. Public Health Nutrition. 4. 3. 847-858.

Boccio, J. R. \& Iyengar, V. (2003). Iron deficiency causes, consequences, and strategies to overcome this nutritional problems. Biological Trace Element Research. 94. 1. 1-32.

British Nutrition Foundation. (2008). Fortification. Retrieved January 7, 2009 from http://www.nutrition.org.uk/home.asp?siteId=43\&sectionId=434\&subSectionId=323\&pa rentSection=299\&which $=$

Brussaard, J. H., Brants, H. A. M., Bouman, M., \& Lowik, M. R. H. (1997). Iron intake and iron status among adults in the Netherlands. European Journal of Clinical Nutrition. 51. 51-58.

Burgess, L., Hackett, A. F., Kirby, S., Maxwell, S., \& Nathan, I. (2001). A reassessment of the fat intake of children from meat and meat products and an estimate of haem iron intake. Journal of Human Nutrition and Dietetics. 14. 1. 55-61. 
Cade, L. E., Burley, V. J., \& Greenwood, D. C. (2004). The UK Women's Cohort Study: Comparison of vegetarians, fish-eaters, and meat-eaters. Public Health Nutrition. 7. 7. 871-878.

Chiplonkar, S. A., Agte, V. V., \& Mengale, S. S. (2003). Relative importance of micronutrient deficiencies in iron deficiency anemia. Nutrition Research. 23. 1355-1367.

Chiplonkar, S. A., Tarwadi, K. V., Kavedia, R. B., Mengale, S. S., Paknikar, K. M., \& Agte, V. V. (1999). Fortification of vegetarian diets for increasing bioavailable iron density using green leafy vegetables. Food Research International. 32. 169-174.

Cook, J. D., \& Reddy, M. B. (2001). Effect of ascorbic acid intake on nonheme-iron absorption from a complete diet. The American Journal of Clinical Nutrition. 73. 93-98.

Cooper, M. J., Cockell, K. A., \& L'Abbe, M. R. (2006). The iron status of Canadian adolescents and adults: Current knowledge and practice implication. Canadian Journal of Dietetic Practice and Research. 67. 3. 130-138.

Cooper, M. J., \& Zlotkin, S. H. (1996). Day-to-day variations of transferrin receptor and ferritin in healthy mean and women. The American Journal of Clinical Nutrition. 64. 738-742.

Davey, G. K., Spencer, E. A., Appleby, P. N., Allen, N. E., Knoex, K. H., \& Key, T. J. (2003). EPIC- Oxford: Lifestyle characteristics and nutrient intake in a cohort of 33,883 meat-eaters and 31,546 non-meat eaters in the UK. Public Health Nutrition. 6. 3. 259268.

Davidsson, L., Dimitriou, T., Walczyk, T., \& Hurrell, R. F. (2001). Iron absorption from experimental infant formulas based on pea (Pisum sativum)-protein isolate: the effect of phytic acid and ascorbic acid. British Journal of Nutrition. 85. 59-63.

Davidsson, L., Walczyk, T., Zavaleta, N., \& Hurrell, R. F. (2001). Improving iron absorption from Peruvian school breakfast meal by adding ascorbic acid or Na2EDTA. The American Journal of Clinical Nutrition. 73. 283-287.

Donovan, U. M., \& Gibson, R. S. (1995). Iron and zinc status of young women aged 14 to 19 years consuming vegetarian and omnivorous diets. Journal of the American College of Nutrition. 14. 5. 463-472.

Dubois, R. W., Goodnough, L. T., Ershler, W. B., Winkle, L. V., \& Nissenson, A. R. (2006). Identification, diagnosis, and management of anemia in adult ambulatory patients treated by primary care Physicians: Evidence-based and consensus recommendations. Current Medical Research and Options. 22. 2. 385-395. 
Due, L., Sinclair, A. J., Mann, N. J., Turner, A., \& Ball, M. J. (2000). Selected micronutrient intake and status in men with differing meat intakes, vegetarians and vegans. The Asian Pacific Journal of Clinical Nutrition. 9. 1. 18-23.

Fairweather-Tait, S. J. (2004). Iron nutrition in the UK: getting the balance right. Proceedings of the Nutrition Society. 63. 519-528.

Fleming, D.J., Jacques, P.F., Massaro, J.M., D'Agostino Sr, R.B., Wilson, P.W.F., \& Wood, R.J. (2001). Aspirin intake and the use of serum ferritin as a measure or iron status. The American Journal of Clinical Nutrition. 74. 219-226.

Fleming, D. J., Jacques, P. F., Tucker, K. L., Massaro, J. M., D’Agostino Sr, R. B., Wilson, P. W. F., et al. (2001). Iron status of the free-living, elderly Framingham Heart Study cohort: an iron-replete population with a high prevalence of elevated iron stores. The American Journal of Clinical Nutrition. 73. 638-646.

Fraser, G.E. (1999). Associations between diet and cancer, ischemic heart disease, and all-cause mortality in non-Hispanic white California Seventh-day Adventists. The American Journal of Clinical Nutrition. 70. 532-538.

Frazer, D. M., \& Anderson, G. J. (2005). Iron imports. I. Intestinal iron absorption and its regulation. American Journal of Physiology Gastrointestinal and Liver Physiology. 289. 631-635.

Frentzel-Beyme, R., \& Chang-Claude, J. (1994). Vegetarian diets and colon cancer: the German experience. The American Journal of Clinical Nutrition. 59. 1143-1152.

Greenwood, D. C., Cade, J. E, Draper, A., Barrett, J. H., Calvert, C., \& Greenhalgh, A. (2000). Seven unique food consumption patterns identified among women in the UK Women's Cohort Study. European Journal of Clinical Nutrition. 54. 314-320.

Haddad, E. H., Berk, L. S., Kettering, J. D., Hubbard, R. W., \& Peters, W. R. (1999). Dietary intake and biochemical, hematologic, and immune status of vegans compared with nonvegetarians. The American Journal of Clinical Nutrition. 70. 586-593.

Hallberg, L., \& Hulthen, L. (2000). Prediction of dietary iron absorption: an algorithm for calculating absorption and bioavailability of dietary iron. The American Journal of Clinical Nutrition. 71. 1147-1160.

Harman, S.K., \& Parnell, W.R. (1998). The Nutritional Health of New Zealand Vegetarians and Non-Vegetarians Seventh-day Adventists: Selected Vitamins, Minerals, and Lipid Levels. The New Zealand Medical Journal. 111. 1062. 91-4.

Harvey, L. J., Armah, C. N., Dainty, J. R., Foxall, R. J., Lewis, D. J., Langford, N. J., et al. (2005). Impact of menstrual blood loss and diet on iron deficiency among women in the UK. British Journal of Nutrition. 94. 557-564. 
Herbert, V. (1992). Iron disorders can mimic anything, so always test for them. Blood Reviews. 3. 125-132.

Huang, Y. C., Lin, W. J., Cheng, C. H., \& Su, K. H. (1999). Nutrient intakes and iron status of healthy young vegetarians and nonvegetarians. Nutritional Research. 19. 5. 663674.

Hunt, J. R., Gallagher, S. K., Johnson, L. K., \& Lykken, G. I. (1995). High-versus lowmeat diets: Effects on zinc absorption, iron status, and calcium, copper, iron, magnesium, manganese, nitrogen, phosphorus, and zinc balance in postmenopausal women. The American Journal of Clinical Nutrition. 62. 621-632.

Hunt, J. R., \& Roughead, Z. K. (1999). Nonheme-iron absorption, fecal ferritin excretion, and blood indexes of iron status in women consuming controlled lactoovovegetarian diets for 8 wk. The American Journal of Clinical Nutrition. 69. 944-952.

Institute of Medicine of the National Academies (IOM). (2004). Dietary Reference Intakes (DRIs); Recommended intake for individuals. Retrieved on November 11, 2006 from http://www.iom.edu/Object.File/Master/21/372/0.pdf.

Johnson, J. M., \& Walker, P. M. (1992). Zinc and iron utilization in young women consuming a beef-based diet. Journal of the American Dietetic Association. 92. 12. 14741479.

Kandiah, J. (2002). Impact of tofu or tofu + orange juice on hematological indices of lacto-ovo vegetarian females. Plant Foods for Human Nutrition. 57. 197-204.

Key, T. J., Fraser, G. E., Thorogood, M., Appleby, P. N., Beral, V., Reeves, G., et al. (1998). Mortality in vegetarians and non-vegetarians: A collaborative analysis of 8,300 deaths among 76,000 men and women in five prospective studies. Public Health Nutrition. 1. 1. 33-41.

Kirk, S. F. L, Cade, J. E., Barrett, J. H, \& Conner, M. (1999). Diet and lifestyle characteristics associated with dietary supplement use in women. Public Health Nutrition. 2. 1. 69-73.

Krajcovicova-Kudlackova, M., Ursinyova, M., Blazicek, P., Spustova, V., Ginter, E., Hladikova, V., et al. (2003). Free radical disease prevention and nutrition. Bratisl Lek Listy. 104. 2. 64-68.

Kristensen, M. B., Hels, O., Morberg, C., Marving, J., Bugel, S., \& Tetens, I. (2005). Pork meat increases iron absorption from a 5-day fully controlled diet when compared to a vegetarian diet with similar vitamin $\mathrm{C}$ and phytic acid content. British Journal of Nutrition. 94. 78-83. 
Larsson, C. L., \& Johansson, G. K. (2002). Dietary intake and nutritional status of young vegans and omnivores in Sweden. The American Journal of Clinical Nutrition. 76. 1. 100-106.

Lea, E., \& Worsley, A. (2001). Influences of meat consumption in Australia. Appetite. 36. 127-136.

Leblanc, J. Ch., Yoon, H., Kombadjian, A., \& Verger, Ph. (2000). Nutritional intake of vegetarian populations in France. European Journal of Clinical Nutrition. 54. 443-449.

Ledikwe, J. H., Blanck, H. M., Khan, K. L., Serdula, M. K., Seymour, J. D., Tohill, B. C., et al. (2006). Low-energy-density diets are associated with high diet quality in adults in the United States. Journal of the American Dietetic Association. 106. 1172-1180.

Li, D., Sinclair, A. J., Mann, N. J., Turner, A., \& Ball, M. J. (2000). Selected micronutrient intake and status in men with differing meat intakes, vegetarians and vegans. Asia Pacific Journal of Clinical Nutrition. 9. 1. 18-23.

Mahan, L. K., \& Escott-Stump, S. (2004). Vegetarians. Krause's Food, Nutrition, \& Diet Therapy (11 ${ }^{\text {th }}$ Edition). 295-298.

Male, C., Persson, L. A., Freeman, V., Guerra, A., van't Hof, M. A., Haschke, F., et al. (2001). Prevalence of iron deficiency in 12-mo-old infants from 11 European areas and influence of dietary factors on iron status (Euro-Growth Study). Acta Paediatr. 90. 492498.

Meirelles, C. M., Veiga, G. V., \& Soares, E. A. (2001). Nutritional status of vegetarian and omnivorous adolescent girls. Nutirional Research. 21. 689-702.

Messina, M., \& Messina, V. (1996). The Dietitian's guide to vegetarian diets issues and applications. New York: Ballantine Books a devision of Randon House Inc. Pages??

Obeid, R., Geisel. J., Schorr, H., Hubner, U., \& Herrmann, W. (2002). The impact of vegetarianism on some haematological parameters. European Journal of Haematology. 69. 275-279.

Palmer, M. E., Haller, C., McKinney, P. E., Klein-Schwartz, W., Tschirgi, A., Smolinske, S. C., et al. (2003). Adverse events associated with dietary supplements: An observational study. The Lancet. 361. 101-106.

Patterson, A. J., Brown, W. J., \& Roberts, D. C. K. (2001). Dietary and lifestyle factors influencing iron stores in Australian women: An examination of the role of bio-available dietary iron. Australian Journal of Nutrition \& Dietetics. 58. 2. 107-114. 
Perry, C. L., McGuire, M. T., Neumark-Sztainer, D., \& Story, M. (2002). Adolescent vegetarians. How well do their dietary patterns meet the Healthy People 2010 Objective? Arch Pediatr Adolesc Med. 156. 431-437.

Pongstaporn, W., \& Bunyaratavej, A. (1999). Hematological parameters, ferritin, and vitamin B12 in vegetarians. Journal of Medical Association of Thailand. 82. 3. 304-311.

Reddy, M. B., \& Cook, J. D. (1997). Effect of calcium intake on nonheme-iron absorption from a complete diet. The American Journal of Clinical Nutrition. 65. 18201825.

Rosado, J. L., Diaz, M., Gonzalez, K., Griffin, I., Abrams, S. A., \& Preciado, R. (2005). The addition of milk or yogurt to a plant-based diet increases zinc bioavailability but does not affect iron bioavailability in women. The Journal of Nutrition. 135. 465-468.

Samuelson, G., Bratteby, L-E., Berggren, K., Elverby, J-E., \& Kempe, B. (1996). Dietary iron intake and iron status in adolescents. Acta Paediatr. 85. 1033-1038.

Shaw, N., Chin, C., \& Pan, W. (1995). A vegetarian diet rich in soybean products compromises iron status in young Students. Journal of Nutrition. 125. 212-219.

Shine, J. W. (1997). Microcytic Anemia. American Family Physician. 55. 7. 2455-2463.

Syed, B A., Sargent, P. J., Farnaud, S., \& Evens, R W. (2006). An overview of molecular aspects of iron metabolism. Hemoglobin. 30. 1. 69-80.

Talyor, A., Redworth, E. W., \& Morgan, J. B. (2004). Influence of diet on iron, copper and zinc status in children under 24 months of age. Biological Trace Element Research. 97. 197-214.

Tarwadi, K., \& Agte, V. (2003). Potential of commonly consumed green leafy vegetables for their antioxidant capacity and its linkage with the micronutrient profile. International Journal of Food Science and Nutrition. 54. 6. 417-425.

Thane, C. W., \& Bates, C. J. (2000). Dietary intake and nutrient status of vegetarian preschool children from a British National Survey. Journal of Human Nutrition and Dietetics. 13. 149-162.

Thane, C. W., Bates, C. J., \& Prentice, A. (2003). Risk factors of low iron intake and poor iron status in a national sample of British young people aged 4-18 years. Public Health Nutrition. 6. 5. 485-496.

Tseng, M., Chakraborty, H., Robinson, D. T., Mendez, M., \& Kohlmeier, L. (1997). Adjustment of iron intake for dietary enhancers and inhibitors in population studies: Bioavailability iron in rural and urban residing Russian women and children. American Society for Nutritional Sciences. 127. 1456-1468. 
U.S. Census Bureau. (2000, December 20). Resident Population Estimates of the United States by Sex, Race, and Hispanic Origin: April 1, 1990 to July 1, 1999. Retrieved October 29, 2008, from http://www.censusbureau.biz/population/estimates/nation/intfile3-1.txt.

U.S. National Library of Medicine and National Institute of Health (U. S. NLM \& NIH). (2007). Anemia, iron deficiency anemia, serum iron, and ferritin. Medline Plus Medical Encyclopedia. Retreived on 3/6/2007 from http://www.nlm.nih.gov/medlineplus/ency/article.

United States Department of Health and Human Services (U. S. DHHS). (2005). Dietary Guidelines for Americans. Retrieved on November 11, 2006 from http://www.health.gov/dietaryguidelines/dga2005/document/.

United States Department of Health and Human Services (U. S. DHHS). (2000). Iron Deficiency and Anemia. Retrieved November 11, 2008 from http://www.healthypeople.gov/Document/HTML/Volume2/19Nutrition.htm\#_Toc49038 3125

The Vegetarian Society. (n.d.). History of vegetarianism. Retrieved on October 29, 2008 from http://www.vegsoc.org/info/developm.html.

Waldmann, A., Koschizke, J. W., Leitzmann, C., \& Hahn, A. (2004). Dietary iron intake and iron status of German female vegans: Results of the German Vegan Study. Annals of Nutrition \& Metabolism. 48. 103-108.

Wells, A. W., Haub, M. D, Fluckey, J., Williams, K., Chernoff, R., \& Campbell, W. W. (2003). Comparisons of the vegetarian and beef-containing diets on hematological indexes and iron stores during a period of resistive training in older men. Journal of the American Dietetic Association. 103. 5. 594-602.

Whittaker, P., Tufaro, P. R., \& Rader, J. I. (2001). Iron and folate in fortified cereals. Journal of the American College of Nutrition. 20. 3. 247-254.

Wilson, A. K., \& Ball, M. J. (1999). Nutrient intake and iron status of Australian male vegetarians. European Journal of Clinical Nutrition. 53. 189-194. 
APPENDICES 
Appendix A

Recruitment Flier posted in Community 

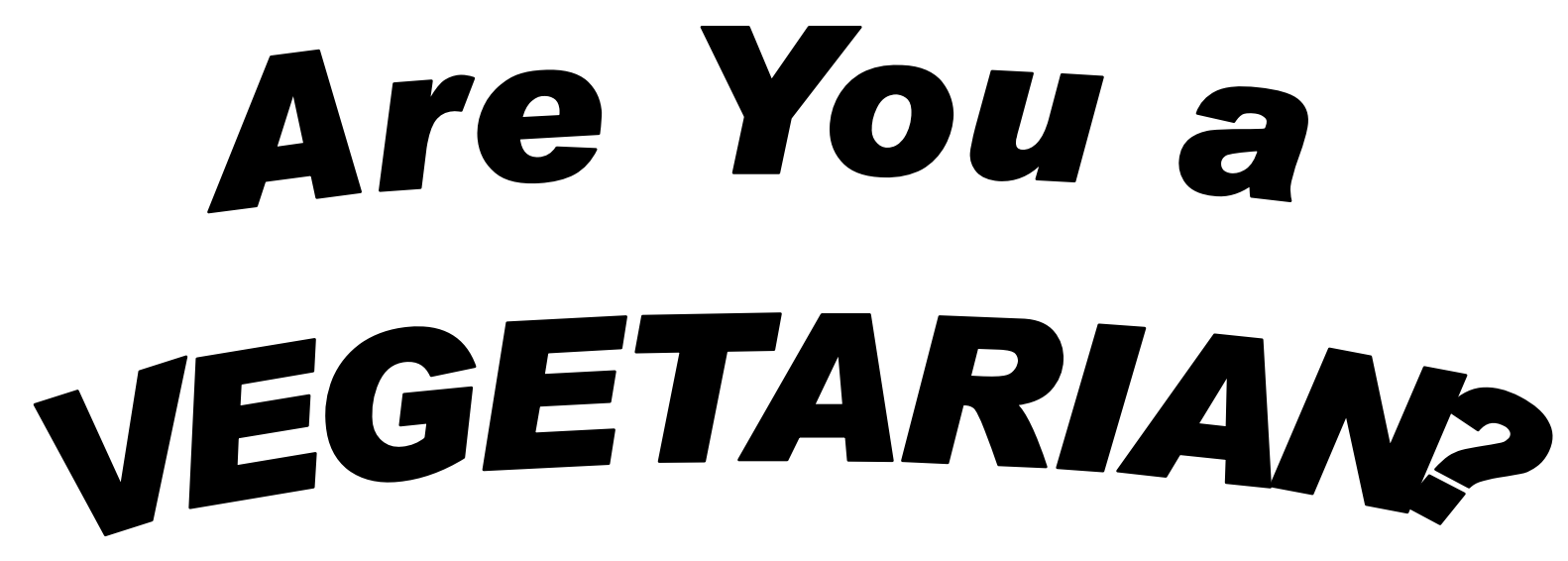

Would you like to know

if you're eating an adequate diet?

\section{Get your FREE Nutrition Analysis}

\& help us to complete a Nutrition Study/Thesis Research Sponsored by the Cal Poly FSN Department

\section{Criteria:}

$\checkmark$ Cal Poly Female Student

$\checkmark$ Age 18-22

$\checkmark$ Vegetarian (no meat)

$\checkmark$ No Vitamin or Mineral Supplements

$\checkmark$ No Medications

$\checkmark$ Limited number of Non-Vegetarian's welcome

Contact Kim Englehardt \& Cindi Small at

\section{nutritionstudy@hotmail.com}

for more information

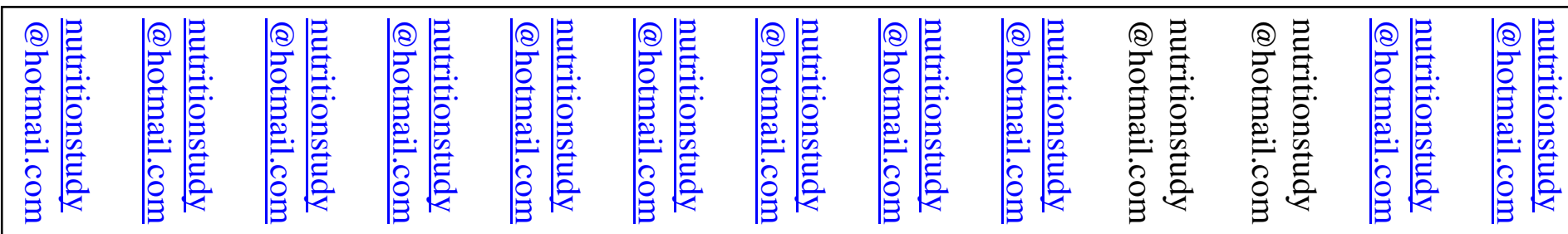


Appendix B

Research Project Informed Consent

For Confidentiality Agreement

Signed by all participants 


\section{INFORMED CONSENT TO PARTICIPATE IN A NUTRITION STUDY OF THE VITAMIN B-12 AND IRON STATUS OF COLLEGE-AGED FEMALES}

A research project on the vitamin B-12 and iron status among college-aged females is being conducted by Master's students, Cindi Small and Kim Englehardt in the Department of Food Science and Nutrition at Cal Poly, San Luis Obispo. The purpose of the study is to compare the vitamin and mineral content among women with different lifestyles and eating habits.

You are being asked to take part in this study by participating in a brief background interview, keeping a dietary food record and giving a blood sample at the Cal Poly Health Center. Your participation will take approximately 3 hours of your time over a several week period. An initial meeting time will be arranged to gather background information and explain the study. You will keep the food record on your own time and return it after the 3-day period. Another time will be scheduled for you to have your blood drawn at the Health Center. Please be aware that you are not required to participate in this research and you may discontinue your participation at any time without penalty.

The possible risks associated with participation in this study include any sensitivity that you may have to giving blood, such as bruising, light-headedness or nausea. If you should experience any of these symptoms or emotional distress, please be aware that you may contact the researchers, Cindi Small at 459-0789, Kim Englehardt at 550-3029 or the Cal Poly Health Center at 756-1211 for assistance.

Your confidentiality will be protected by not disclosing your name to anyone except the researchers. Your name will not be revealed with the results of the study. The files will be kept under lock and key at all times and only be accessible to Cindi Small, Kim Englehardt the researchers, or Dr. Susan Hawk (faculty advisor). Potential benefits associated with the study include a complimentary nutritional analysis based on your dietary food record and a complete laboratory panel of your blood work as required by this study.

If you have questions regarding this study or would like to be informed of the results when the study is completed, please feel free to contact Cindi Small at 459-0789, Kim Englehardt at 550-3029 and/or Dr. Susan Hawk in the Food Science and Nutrition Department at 756-2660. If you have questions or concerns regarding the manner in which the study is conducted, you may contact Steve Davis, Chair of the Cal Poly Human Subjects Committee, at 756-2754, sdavis@ calpoly.edu, or Susan Opava, Dean of Research and Graduate Programs, at 756-1508, sopava@calpoly.edu.

If you agree to voluntarily participate in this research project as described, please indicate your agreement by signing below and completing the background questionnaire. Please keep one copy of this form for your reference, and thank you for your participation in this research.

Signature of Volunteer

Signature of Researcher

$\frac{\text { Date }}{\text { Date }}$


Appendix C

Research Project Background Questionnaire

For Assessing Eligibility

Obtaining Characteristic and Anthropometric Data 


\section{Background Information Questionnaire}

Participant Name Gender: Female

Major Age

D.O.B.

Marital Status: Married or Single (circle one) Living Arrangement: Alone or Roommates

Menstrual Period Cycle days Regular or Irregular (circle one)

First day of last menstrual period (month, day)

\section{Please circle the best answer for each question below:}

1. What is your diet type?

a) regular

b) pesco-vegetarian (eat fish, but no meats)

c) lacto-ovo vegetarian (eat dairy and eggs, but no fish or meats)

d) other

2. Do you take any supplements?

a) yes (how often and what type?)

b) no

c) sometimes (how often and what type?)

3. Do you take a multivitamin?

a) yes (how often and brand?)

b) no

c) sometimes (how often and what type?)

4. Do you take any prescribed medications (including birth control)?

a) yes (how often and what for?)

b) no

c) sometimes (how often and what type?)

5. Are you pregnant?

a) yes

b) no

6. Do you have any medical or health conditions?

a) yes (please describe)

b) no

7. Have you ever been diagnosed with anemia?

a) yes (when and did it get corrected?)

b) no

c) not officially, but I suspect that I have been anemic at one time or another 
8. How often do you eat out (including on campus)?
a) never
b) less than 3 times per week
c) more than 5 times per week
d) everyday
e) every meal
f) other

9. How many cigarettes do you smoke?
a) none
b) a few per week
c) about half a pack a day
c) pack a day
e) more than a pack a day

10. How often do you drink alcoholic beverages?
a) never
b) less than 5 per week
c) more than 5 per week

11. How would you describe your average activity level?

a) Very Light (every day household chores or walking to class, etc.)

b) Light (Walking for a long distance $2.5-3.0 \mathrm{mph}$, dancing, golf, etc.)

c) Moderate (walking a long distance $3.5-4.0 \mathrm{mph}$, gardening, tennis, skiing, etc.)

d) Heavy (jump rope, heavy manual labor, climbing, soccer, cross country skiing, etc.)

e) Very Heavy (athlete training or professional events)

12. Describe your regular exercise routine:

Cardiovascular (how long and how often?)

Weight Lifting (how long and how often?)

13. Describe any irregular exercise that you do:

Irregular Exercise (what activity, how long and how often?)

Additional Comments:

\section{DO NOT WRITE BELOW THIS LINE}

\section{RESEARCHER USE ONLY:}

Weight:

Height

Blood donation time

Follow up meeting time 
Appendix D

Food Frequency Questionnaire Used to Verify Diet Type 
Think about your most recent earing habits and how often you eat each of the following
toods. Please mark one circle for each food

\begin{tabular}{|c|c|c|c|c|c|}
\hline Protein Sources & $\begin{array}{c}\text { 1/MONTH } \\
\text { or less }\end{array}$ & $\begin{array}{c}2-3 \text { times a } \\
\text { MONTH }\end{array}$ & $\begin{array}{c}1-2 \text { times a } \\
\text { WEEK }\end{array}$ & $\begin{array}{c}3-4 \text { times a } \\
\text { WEEK }\end{array}$ & $\begin{array}{c}5+\text { times a } \\
\text { WEEK }\end{array}$ \\
\hline Beef, Veal (roast, steak, cubes) & 0 & 0 & 0 & $\mathrm{O}$ & 0 \\
\hline Pork & 0 & 0 & 0 & 0 & $\mathrm{O}$ \\
\hline Ham & 0 & 0 & $\mathrm{O}$ & $\mathrm{O}$ & 0 \\
\hline Lean lunch meat & 0 & $\mathrm{O}$ & 0 & $\mathrm{O}$ & $\mathrm{O}$ \\
\hline Poultry (chicken or turkey) not fried & 0 & 0 & $\mathrm{O}$ & $\mathrm{O}$ & $\mathrm{O}$ \\
\hline Salmon & $\mathrm{O}$ & 0 & $\mathrm{O}$ & $\mathrm{O}$ & 0 \\
\hline Fish, white & 0 & 0 & $\mathrm{O}$ & $\mathrm{O}$ & 0 \\
\hline $\begin{array}{l}\text { Shcllfish (crab, lobster, shrimp or } \\
\text { scallops) }\end{array}$ & $\mathrm{O}$ & $\mathrm{O}$ & $\mathrm{O}$ & $\mathrm{O}$ & $\mathrm{O}$ \\
\hline $\begin{array}{l}\text { Soy protein meat substitute (ex. vegetarian } \\
\text { burgers) }\end{array}$ & 0 & 0 & 0 & $\mathrm{O}$ & 0 \\
\hline $\begin{array}{l}\text { Beans, legumes (baked beans, pinto, kiôney } \\
\text { or black lentils) }\end{array}$ & $\mathrm{O}$ & 0 & $\mathrm{O}$ & $\mathrm{O}$ & 0 \\
\hline Egg substitute & 0 & 0 & 0 & $\mathrm{O}$ & $\mathrm{O}$ \\
\hline Eggs & 0 & $\mathrm{O}$ & $\mathrm{O}$ & $\mathrm{O}$ & $\mathrm{O}$ \\
\hline Gound beef, hamburgers, meatbalis or tacos & 0 & $\mathrm{O}$ & 0 & $\mathrm{O}$ & $\mathrm{O}$ \\
\hline Ground turkey or chicken & 0 & $\mathrm{O}$ & $\mathrm{O}$ & $\mathrm{O}$ & 0 \\
\hline Fried chicken & 0 & O & $\mathrm{O}$ & $\mathrm{O}$ & O \\
\hline Hot Dogs (regular), Polish or Italian & $\mathrm{O}$ & $\mathrm{O}$ & 0 & $\mathrm{O}$ & $\mathrm{O}$ \\
\hline sausage & 0 & $\mathrm{O}$ & 0 & 0 & 0 \\
\hline Pepperoni, salami or bologna & $\mathrm{O}$ & $\mathrm{O}$ & $\mathrm{O}$ & $\mathrm{O}$ & $\mathrm{O}$ \\
\hline Bacon, breakfast sausage or scapple & $\mathrm{O}$ & $\mathrm{O}$ & $\mathrm{O}$ & $\mathrm{O}$ & $\mathrm{O}$ \\
\hline Peanut butter & 0 & $\mathrm{O}$ & $\mathrm{O}$ & $\mathrm{O}$ & $\mathrm{O}$ \\
\hline Nuts (peanuts, cashews, almonds etc) & 0 & 0 & O & $\mathrm{O}$ & 0 \\
\hline Starches & $\begin{array}{c}\text { 1/WONTH } \\
\text { or less }\end{array}$ & $\begin{array}{c}2-3 \text { times a } \\
\text { MONTH }\end{array}$ & $\begin{array}{c}1-2 \text { times a } \\
\text { WEEK }\end{array}$ & $\begin{array}{c}3-4 \text { times a } \\
\text { WEEK }\end{array}$ & $\begin{array}{c}5+\text { times a } \\
\text { WEEK }\end{array}$ \\
\hline White bread & 0 & 0 & 0 & $\mathrm{O}$ & $\mathrm{O}$ \\
\hline Dinner roll & 0 & 0 & 0 & 0 & $\mathrm{O}$ \\
\hline Whole wheat bread or rye & $\mathrm{O}$ & $\mathrm{O}$ & $\mathrm{O}$ & $\mathrm{O}$ & $\mathrm{O}$ \\
\hline Pasta & $\mathrm{O}$ & $\mathrm{O}$ & $\mathrm{O}$ & $\mathrm{O}$ & $\mathrm{O}$ \\
\hline Rice & 0 & $\mathrm{O}$ & 0 & 0 & 0 \\
\hline Bagel, large & $\mathrm{O}$ & $\mathrm{O}$ & $\mathrm{O}$ & $\mathrm{O}$ & $\mathrm{O}$ \\
\hline Bagel. small & 0 & 0 & 0 & 0 & $\mathrm{O}$ \\
\hline Pretzels & $\mathrm{O}$ & 0 & 0 & $\mathrm{O}$ & $\mathrm{O}$ \\
\hline Crackers, or snack crackers & 0 & $\mathrm{O}$ & 0 & $\mathrm{O}$ & $\mathrm{O}$ \\
\hline Hot cereal (oatmeal, farina) & 0 & 0 & $\mathrm{O}$ & $\mathrm{O}$ & $\mathrm{O}$ \\
\hline Cold cereal, sweetened (ex. Frosted Flakes) & $\mathrm{O}$ & 0 & $\mathrm{O}$ & 0 & $\mathrm{O}$ \\
\hline $\begin{array}{l}\text { Cold cereal, high fiber (ex. Shredded wheat or } \\
\text { Raisin Bran) }\end{array}$ & $\mathrm{O}$ & $\mathrm{O}$ & 0 & $\mathrm{O}$ & $\mathrm{O}$ \\
\hline Baked, boiled or mashed potato & $\mathrm{O}$ & $\mathrm{O}$ & $\mathrm{O}$ & 0 & $\mathrm{O}$ \\
\hline Pancakes or waffles & $\mathrm{O}$ & 0 & 0 & $\mathrm{O}$ & 0 \\
\hline
\end{tabular}




\begin{tabular}{|c|c|c|c|c|c|}
\hline Fruits and Vegetables & $\begin{array}{c}1 / \mathrm{MONTH} \\
\text { or less }\end{array}$ & $\begin{array}{c}2-3 \text { times a } \\
\text { MONTH }\end{array}$ & $\begin{array}{l}\text { 1-2 times a } \\
\text { WEEK }\end{array}$ & $\begin{array}{c}\text { 3-4 times a } \\
\text { WEEK }\end{array}$ & $\begin{array}{c}5+\text { times a } \\
\text { WEEK }\end{array}$ \\
\hline Raw fruit & 0 & $\mathrm{O}$ & $\mathrm{O}$ & $\mathrm{O}$ & 0 \\
\hline $\begin{array}{l}100 \% \text { fruit juice, like apple or orange (frozen } \\
\text { or canned) }\end{array}$ & 0 & 0 & $\mathrm{O}$ & 0 & 0 \\
\hline Canned fruit & 0 & 0 & 0 & $\mathrm{O}$ & $\mathrm{O}$ \\
\hline Dried fruit & 0 & 0 & 0 & 0 & 0 \\
\hline Green salad & $\mathrm{O}$ & 0 & 0 & $\mathrm{O}$ & $\mathrm{O}$ \\
\hline Vegetable juice & $\mathrm{O}$ & $\mathrm{O}$ & $\mathrm{O}$ & $\mathrm{O}$ & 0 \\
\hline Vegetable soup or stew with vegetables & 0 & 0 & 0 & $\mathrm{O}$ & $\mathrm{O}$ \\
\hline Tomato sauce & $\mathrm{O}$ & 0 & $\mathrm{O}$ & 0 & 0 \\
\hline Cooked vegetables & 0 & $\mathrm{O}$ & $\mathrm{O}$ & $\mathrm{O}$ & $\mathrm{O}$ \\
\hline Raw vegetables & $\mathrm{O}$ & $\mathrm{O}$ & 0 & $\mathrm{O}$ & 0 \\
\hline
\end{tabular}

\begin{tabular}{|c|c|c|c|c|c|}
\hline Dairy Products & $\begin{array}{l}\text { I/MONTH } \\
\text { or less }\end{array}$ & $\begin{array}{c}2-3 \text { times a } \\
\text { MONTH }\end{array}$ & $\begin{array}{l}1-2 \text { times a } \\
\text { WEEK }\end{array}$ & $\begin{array}{l}3-4 \text { times a } \\
\text { WEEK }\end{array}$ & $\begin{array}{c}5+\text { times a } \\
\text { WEEK }\end{array}$ \\
\hline Milk (Please circle skim, $1 \%, 2 \%$ or whole) & $\mathrm{O}$ & $\mathrm{O}$ & $\mathrm{O}$ & $\mathrm{O}$ & $\mathrm{O}$ \\
\hline Cheese & 0 & $\mathrm{O}$ & $\mathrm{O}$ & $\mathrm{O}$ & 0 \\
\hline Cottage cheese & $\mathrm{O}$ & 0 & 0 & 0 & 0 \\
\hline Yogurt (not frozen) & 0 & $\mathrm{O}$ & 0 & $\mathrm{O}$ & O \\
\hline Combination Foods / Other & $\mathrm{O}$ & 0 & 0 & $\mathrm{O}$ & $\mathrm{O}$ \\
\hline Pizza & 0 & 0 & $\mathrm{O}$ & $\mathrm{O}$ & $\mathrm{O}$ \\
\hline French Fries, hash browns & $\mathrm{O}$ & $\mathrm{O}$ & $\mathrm{O}$ & $\mathrm{O}$ & $\mathrm{O}$ \\
\hline $\begin{array}{l}\text { Frozen food entrée (ex. Stouffers, Lean } \\
\text { Cuisine) }\end{array}$ & $\mathrm{O}$ & 0 & $\mathrm{O}$ & $\mathrm{O}$ & 0 . \\
\hline Lasagna, Chili & 0 & 0 & $\mathrm{O}$ & $\mathrm{O}$ & 0 \\
\hline Chinese Food & $\mathrm{O}$ & $\mathrm{O}$ & $\mathrm{O}$ & $\mathrm{O}$ & 0 \\
\hline
\end{tabular}

\begin{tabular}{|c|c|c|c|c|c|}
\hline Fats, Oils and Sweets & $\begin{array}{c}1 / \mathrm{MONTH} \\
\text { or less }\end{array}$ & $\begin{array}{l}2-3 \text { times a } \\
\text { MONTH }\end{array}$ & $\begin{array}{c}1-2 \text { times a } \\
\text { WEEK }\end{array}$ & $\begin{array}{c}3-4 \text { times a } \\
\text { WEEK }\end{array}$ & $\begin{array}{l}5+\text { times a } \\
\text { WEEK }\end{array}$ \\
\hline Ice cream (not low fat or fat free) & $\mathrm{O}$ & 0 & 0 & $\mathrm{O}$ & $\mathrm{O}$ \\
\hline Potato chips, nacho chips, flavored popcorn, etc. & $\mathrm{O}$ & $\mathrm{O}$ & $\mathrm{O}$ & $\mathrm{O}$ & $\mathrm{O}$ \\
\hline Donuts, pastries or danishes & 0 & 0 & O & $\mathrm{O}$ & $\mathrm{O}$ \\
\hline Muffins (not low fat or fat free) & $\mathrm{O}$ & $\mathrm{O}$ & 0 & $\mathrm{O}$ & $\mathrm{O}$ \\
\hline Cookies & 0 & 0 & 0 & $\mathrm{O}$ & $\mathrm{O}$ \\
\hline Cake or pie & $\mathrm{O}$ & $\mathrm{O}$ & $\mathrm{O}$ & $\mathrm{O}$ & $\mathrm{O}$ \\
\hline Chocolate or chocolate bar & 0 & $\mathrm{O}$ & 0 & $\mathrm{O}$ & $\mathrm{O}$ \\
\hline Salad dressing (fat free or light) & $\mathrm{O}$ & $\mathrm{O}$ & 0 & $\mathrm{O}$ & $\mathrm{O}$ \\
\hline Salad dressing (regular) & 0 & $\mathrm{O}$ & $\mathrm{O}$ & $\mathrm{O}$ & $\mathrm{O}$ \\
\hline Mayonnaise (regular) & 0 & O & 0 & $\mathrm{O}$ & $\mathrm{O}$ \\
\hline Butter, margarine or oil (in cooking) & 0 & $\mathrm{O}$ & 0 & $\mathrm{O}$ & $\mathrm{O}$ \\
\hline Butter or margarine (on bread or as a condiment) & $\mathrm{O}$ & $\mathrm{O}$ & $\mathrm{O}$ & $\mathrm{O}$ & $\mathrm{O}$ \\
\hline Cream cheese or sour cream & 0 & 0 & 0 & $\mathrm{O}$ & 0 \\
\hline Hard Candy & 0 & $\mathrm{O}$ & 0 & $\mathrm{O}$ & $\mathrm{O}$ \\
\hline Jelly & 0 & $\mathrm{O}$ & 0 & 0 & 0 \\
\hline $\begin{array}{l}\text { Soda or sugar sweetened beverage (ex. Iced } \\
\text { tea) }\end{array}$ & 0 & $\mathrm{O}$ & $\mathrm{O}$ & $\mathrm{O}$ & $\mathrm{O}$ \\
\hline
\end{tabular}




\section{Appendix E}

\section{Food Record Instructions}

Food Record Worksheet: Used for each day of food record 


\section{Food Record Instructions}

\section{The following instructions will help to ensure a complete and accurate food record.}

- Please record all foods and drinks that you have for three days: two weekdays and one weekend day if possible. Do not change your eating habits for this food record. Be sure to include any late night meals, snacks or drinks.

- Use a separate sheet for each day of the food record. Multiple sheets are included.

- Record the approximate time each meal or snack is eaten.

- Make sure to record all beverages that you consume and be sure to include description and size. This also includes no calorie drinks such as diet colas, unsweetened iced tea or water.

- Carry the food record with you during the day and document your meals and snacks soon after you eat.

- List foods and drinks as soon as possible after consuming them to prevent forgetting something you ate or drank.

- Be specific about how the food was prepared. Write down anything added while cooking or at the table. This would include: butter, oil, spices, cheese, etc.

- Please write down brand names of the products you eat so we can match them up exactly in our database of foods.

- Write down the weight per serving from the package of the products that you eat (grams or ounces).

- Use the guidelines included in this packet to determine the size of your servings. Or if you find it difficult to judge, describe the portion as a deck of cards, baseball, golf ball, etc...

- If you eat food from a restaurant, please include the name of the restaurant. Remember to record the size of your serving (supersize, large, medium, small) and how your meal was prepared (fried, baked, broiled...)

- If you eat combination foods, such as pizza, sandwich, burrito, etc...make sure to record all the different toppings or ingredients. 
- If you run out of room on the front of the food record in a specific section, use the back of the paper or attach a new piece of paper to the record. Don't leave anything out trying to save space.

- Do not fill in the food record on a non-typical day. If you are sick or on a schedule for a day that doesn't allow you to eat as you usually do, don't fill out the food record on that day, wait for a typical day to record your food intake.

- Remember to bring the completed food record to the follow-up meeting. You may want to make and keep a copy for yourself.

- If you have any questions during the keeping of the food record, contact Cindi Small or Kim Englehardt at nutritionstudy@ hotmail.com. 


\section{CALPOLY \\ California Polytechnic State University}

San Luis Obispo, CA 93407

Name:

Breakfast

\begin{tabular}{|c|c|c|}
\hline Time/Mood & Type of Food & Amount of Food \\
\hline & & \\
\hline & & \\
\hline & & \\
\hline
\end{tabular}

Lunch

\begin{tabular}{|l|r|r|}
\hline Time/Mood & Type of Food & Amount of Food \\
\hline & & \\
\hline & & \\
\hline & & \\
\hline
\end{tabular}

Dinne:

\begin{tabular}{|c|c|c|}
\hline Time/Mood & Tyje of Food & Anuount of Food \\
\hline & & \\
\hline & & \\
\hline & & \\
\hline
\end{tabular}

Sracks

\begin{tabular}{|c|c|c|}
\hline Tine/Mood & Type af Food & Anomat of Food \\
\hline & & \\
\hline & & \\
\hline & & \\
\hline & & \\
\hline & & \\
\hline
\end{tabular}




\section{Appendix F}

Food Record Reference List

Used for assistance when recording food intake 


\section{Food Record Reference List}

This list is designed to assist you in completing your Daily Food Record--

As you record the foods you have eaten at each meal, please be specific and use this list as a guide to how a serving would typically be entered.

Breads, Cereals, Grain Products

\begin{tabular}{|l|l|}
\hline Serving Size & Food Name / Description \\
\hline 1 slice & Whole wheat bread \\
\hline 1 slice, 1 each & Sourdough or French bread/roll \\
\hline 1 slice, $1 / 2$ bun & White bread, hamburger or hot-dog bun \\
\hline 4 to 6 each & Whole grain crackers (Triscuits, Wheat Thins, Rye Krisp) \\
\hline $\begin{array}{l}4 \text { to } 6 \text { each, } \\
40 \text { each }\end{array}$ & $\begin{array}{l}\text { Refined crackers (Saltines, cheese, Ritz), or } \\
\text { Oyster crackers }\end{array}$ \\
\hline $\begin{array}{l}2 \text { each, } \\
7 \text { each }\end{array}$ & $\begin{array}{l}\text { Graham crackers, or } \\
\text { Animal crackers }\end{array}$ \\
\hline 1 each & Tortilla, corn, $6^{\prime \prime}$ diameter \\
\hline 1 each & Tortilla, flour, medium \\
\hline 1 each & Muffins (corn, bran, blueberry) \\
\hline $1 / 2$ each & English muffin, pita bread, $3^{\prime \prime}$ diameter bagel \\
\hline 1 each & Pancakes, $4^{\prime \prime}$ diameter or Waffles, $7^{\prime \prime}$ diameter \\
\hline $1 / 2$ cup & Whole grain hot cereal (rolled oats, rolled wheat, Roman Meal) \\
\hline $1 / 2$ cup & Refined hot cereal (cream of wheat, cream of rice) \\
\hline $1 / 2$ cup or & Instant hot cereal \\
1 package & Cold cereals, no sugar (shredded wheat, corn flakes), \\
\hline $3 / 4$ cup, or & Grapenuts \\
\hline $1 / 4$ cup & Bran type cold cereals (raisin bran, bran flakes, All Bran) \\
\hline $3 / 4$ cup & Sweetened cold cereals (Frosted Flakes, Apple Jacks) \\
\hline $3 / 4$ cup & Granola \\
\hline $1 / 2$ cup & Brown rice, cooked \\
\hline $1 / 2$ cup & White rice, cooked \\
\hline $1 / 2$ cup & Pastas, cooked (macaroni, spaghetti, noodles) \\
\hline $1 / 2$ cup & \\
\hline
\end{tabular}

\begin{tabular}{|l|l|}
\hline Serving Size & Food Name / Description \\
\hline $1 / 2$ cup & Orange or grapefruit, unsweetened \\
\hline $1 / 2$ cup & Tomato or V -8 \\
\hline $1 / 2$ cup & Other, unsweetened (apple, grape, pineapple) \\
\hline $1 / 2$ cup & Sweetened juices or nectars \\
\hline
\end{tabular}

\begin{tabular}{|l|l|}
\hline Serving Size & Food Name / Description \\
\hline 1 each & Apple, fresh, medium \\
\hline 1 each & Banana, medium \\
\hline
\end{tabular}

Food Record Reference List 


\begin{tabular}{|l|l|}
\hline 1 each, or & Citrus fruit \\
$1 / 2$ each & Grapefruit \\
\hline 1 each, or & Peaches \\
1 each & Nectarines \\
3 each & Apricots \\
2 each & Plums \\
10 each & Cherries \\
\hline 1 cup & Berries \\
\hline $1 / 4$ each or 1 cup & Cantaloupe, medium \\
\hline 1 cup & Melons (watermelon, honeydew, casaba) \\
\hline 1 each & Pears, fresh, medium \\
\hline $1 / 2$ cup & Pineapple, fresh \\
\hline 1 cup & Grapes, fresh \\
\hline 2 tbsp & Dried fruits: Raisins \\
2 each & Dates \\
2 each & Prunes \\
4 each & Apricots \\
\hline $1 / 2$ cup & Canned or frozen unsweetened fruit \\
\hline $1 / 2$ cup & Canned or frozen sweetened fruit \\
\hline
\end{tabular}

\begin{tabular}{|l|l|}
\hline Serving Size & Food Name / Description \\
\hline 1 tbsp & Vegetable oils (corn, safflower, soy) \\
\hline 1 tbsp & Olive oil \\
\hline 1 tbsp & Shortening, vegetable \\
\hline 1 tbsp & Lard \\
\hline 1 tsp & Margarine \\
\hline 1 tsp & Butter \\
\hline 5 each & Olives \\
\hline $1 / 8$ each & Avocado (1/6=5 grams of fat and 51 Kcal.) \\
\hline 1 tbsp & Mayonnaise \\
\hline 1 tbsp & Regular salad dressings \\
\hline 1 tbsp & Low-calorie dressings \\
\hline 1 tbsp & Sour cream \\
\hline 1 tbsp & Cream cheese \\
\hline 1 tbsp & Half \& Half \\
\hline 1 tbsp & Whipping cream \\
\hline 1 tbsp & Coffee whitener, imitation cream \\
\hline 2 slices & Bacon \\
\hline
\end{tabular}

\begin{tabular}{|l|l|}
\hline Serving Size & Food Name / Description \\
\hline 1 cup & Nonfat milk \\
\hline 1 cup & Lowfat (2\%) milk \\
\hline 1 cup & Whole milk \\
\hline 1 cup & Chocolate lowfat milk \\
\hline 1 cup & Buttermilk \\
\hline 1 cup & Yogurt, lowfat plain \\
\hline 1 cup & Yogurt, lowfat with fruit \\
\hline 1 cup & Yogurt, nonfat plain \\
\hline
\end{tabular}

Food Record Reference List 


\begin{tabular}{|l|l|}
\hline 1 ounce & Cheeses (cheddar, colby, american, monterey jack) \\
\hline 1 ounce & Cheeses, lower fat (swiss, mozzarella, ricotta, string) \\
\hline $1 / 2$ cup & Cottage cheese, regular \\
\hline $1 / 2$ cup & Cottage cheese, lowfat \\
\hline 1 ounce & Lunch meats (bologna, salami, etc.) \\
\hline $\begin{array}{l}1 \text { each, or } \\
2 \text { each }\end{array}$ & $\begin{array}{l}\text { Frankfurters, or } \\
\text { Sausage links }\end{array}$ \\
\hline
\end{tabular}

\begin{tabular}{|l|l|}
\hline Serving Size & Food Name / Description \\
\hline 2 each & Cookies (chocolate chip, oatmeal, peanut butter) \\
\hline 1 each & Brownies, 1 1/2 inch by 1 inch \\
\hline 1 each & Doughnut or sweetroll \\
\hline 1 each & Cake without icing, 3 inches by 2 inches \\
\hline 1 each & Cake with icing, 3 inches by 2 inches \\
\hline 1 each & Granola bars \\
\hline 1 slice & Pie, $1 / 8$ of whole pie \\
\hline $1 / 2$ cup & Jell-O, regular, sugar-sweetened \\
\hline $1 / 2$ cup & Jell-O, diet, no sugar \\
\hline $1 / 2$ cup & Pudding or custard \\
\hline $1 / 2$ cup & Ice cream \\
\hline $1 / 2$ cup & Ice milk \\
\hline $1 / 2$ cup & Sherbet \\
\hline 1 each & Popsicles \\
\hline $11 / 2$ ounce & Candy bar, chocolate, M \& Ms \\
\hline $11 / 2$ ounce & Hard candy, gum drops, Lifesavers \\
\hline 12 fl. oz. & Milkshake \\
\hline
\end{tabular}

\begin{tabular}{|l|l|}
\hline Serving Size & Food Name / Description \\
\hline 1 slice & Pizza \\
\hline 2 cups & Popcorn, popped without oil \\
\hline 2 cups & Popcorn, popped with oil \\
\hline 1 ounce, or about 10 & Potato chips, corn chips, tortilla chips \\
\hline 1 tbsp & Catsup or chili sauce \\
\hline $1 / 2$ cup & Tomato sauce \\
\hline 5 slices, or & Pickles, or \\
1 tbsp & Pickle relish \\
\hline 1 stick & Chewing gum, with or without sugar \\
\hline 1 tbsp & Sauces (soy sauce, steak sauce, barbecue sauce) \\
\hline $1 / 4$ cup & Gravy (brown, giblet, white sauce) \\
\hline 1 cup & Soups (vegetable or noodle type) \\
\hline 1 cup & Soups (cream type) \\
\hline 1 each & Fast foods (hamburgers, tacos) Specify brand name and item \\
\hline 1 tbsp & Sugar, honey, jam, jelly, syrups \\
\hline
\end{tabular}


Appendix G

Blood Draw Instructions 
Participant name

Blood Draw Appointment

\section{Blood Draw Instructions}

The days and times available for a blood draw are Mondays and Fridays starting at 8:00 A.M. and Tuesday, Wednesday, and Thursday starting at 9:00 A.M.

1. The blood draw requires a 12 hour fast. Do not eat anything past 8:00 or 9:00 P.M. the night before your blood draw appointment (depending on time of appointment). Take a snack to eat with you for after the blood draw.

2. Go to the campus Health Center, Bldg. 27 and enter on the upper floor. Take the first left and the laboratory window is on your right. Tell the person at the window you are there for the Cal Poly Nutrition Study for Cindi Small and/or Kim Englehardt to have your blood drawn.

3. Take your student I.D. with you. You will be checked off then list, and then the staff will take care of you from that point.

4. If you need to contact the Health Center, please call 756-1211 and ask for the laboratory. Or if you need assistance or miss your appointment, please contact Cindi Small at 459-0789 or Kim Englehardt at 550-3029 or email nutritionstudy@ hotmail.com.

5. Please email Cindi Small and/or Kim Englehardt at nutritionstudy@ hotmail.com to confirm that you completed the blood draw and to schedule your follow-up meeting if you haven't done so already. 